\title{
Comparison of ice cloud properties simulated by the Community Atmosphere Model (CAM5) with in-situ observations
}

\author{
T. Eidhammer, H. Morrison, A. Bansemer, A. Gettelman, and A. J. Heymsfield \\ National Center for Atmospheric Research, P.O. Box 3000, Boulder, CO 80307, USA \\ Correspondence to: T. Eidhammer (trude@ucar.edu)
}

Received: 23 December 2013 - Published in Atmos. Chem. Phys. Discuss.: 20 March 2014

Revised: 25 June 2014 - Accepted: 17 August 2014 - Published: 23 September 2014

\begin{abstract}
Detailed measurements of ice crystals in cirrus clouds were used to compare with results from the Community Atmospheric Model Version 5 (CAM5) global climate model. The observations are from two different field campaigns with contrasting conditions: Atmospheric Radiation Measurements Spring Cloud Intensive Operational Period in 2000 (ARM-IOP), which was characterized primarily by midlatitude frontal clouds and cirrus, and Tropical Composition, Cloud and Climate Coupling (TC4), which was dominated by anvil cirrus. Results show that the model typically overestimates the slope parameter of the exponential size distributions of cloud ice and snow, while the variation with temperature (height) is comparable. The model also overestimates the ice/snow number concentration (0th moment of the size distribution) and underestimates higher moments (2nd through 5th), but compares well with observations for the 1st moment. Overall the model shows better agreement with observations for TC4 than for ARM-IOP in regards to the moments. The mass-weighted terminal fall speed is lower in the model compared to observations for both ARM-IOP and TC4, which is partly due to the overestimation of the size distribution slope parameter. Sensitivity tests with modification of the threshold size for cloud ice to snow autoconversion $\left(D_{\mathrm{cs}}\right)$ do not show noticeable improvement in modeled moments, slope parameter and mass weighed fall speed compared to observations. Further, there is considerable sensitivity of the cloud radiative forcing to $D_{\mathrm{cs}}$, consistent with previous studies, but no value of $D_{\mathrm{cs}}$ improves modeled cloud radiative forcing compared to measurements. Since the autoconversion of cloud ice to snow using the threshold size $D_{\text {cs }}$ has little physical basis, future improvement to combine cloud ice and snow into a single category, eliminating the need for autoconversion, is suggested.
\end{abstract}

\section{Introduction}

The parameterization of cloud microphysics plays a critical role in general circulation model (GCM) simulations of climate (e.g. Stephens, 2005). Ice microphysics in particular plays an important role in the global radiative balance (e.g. Mitchell et al., 2008; Zhao et al., 2013), since its parameterization strongly impacts the microphysical and hence radiative properties of ice clouds. It also strongly affects mixedphase cloud properties, with impacts on precipitation formation and conversion of liquid to ice.

Because traditional GCMs are unable to resolve smallerscale features that drive cloud processes, and because of the need for computationally efficiency for climate simulations, the parameterization of microphysics in these models has historically been highly simplified. The first GCMs specified cloud properties diagnostically (e.g. see review in Stephens, 2005). In later decades GCMs treated one or more species of cloud water, with precipitation water treated diagnostically (Ghan and Easter, 1992; Rotstayn, 1997; Rasch and Kristjansson, 1998) or prognostically (Fowler et al., 1996; Posselt and Lohmann, 2008). Several earlier schemes partitioned the total condensate into liquid and ice diagnostically as a function of temperature (Del Genio, 1996). More recently schemes have begun to separately prognose liquid and ice, with an explicit representation of various processes converting water mass between liquid and ice such as freezing, riming, and the Bergeron-Findeisen-Wegener process (Fowler et al., 1996; Lohmann and Roeckner, 1996; Rotstayn et al., 2000; Morrison and Gettelman, 2008; Gettelman et al., 2010). To represent cloud-aerosol interactions and impacts on droplet and ice crystal sizes and hence radiative properties, additional complexity has been added to GCM microphysics schemes to prognose both mass and number 
mixing ratios of cloud droplets and ice (Ghan et al., 1997; Lohmann et al., 1999; Liu and Penner, 2005; Ming et al., 2007; Morrison and Gettelman, 2008). Thus, there has been a steady march toward increasing complexity of microphysics schemes in GCMs.

Nonetheless, several aspects of microphysics remain uncertain. In addition to important issues related to the inability of GCMs to resolve cloud-scale processes, there are underlying uncertainties in the microphysical processes themselves, especially for the ice phase. These uncertainties present challenges, not only for GCMs but also for models of all scales. Much of this uncertainty is rooted in the wide variety of ice particle shapes and types that occur in the atmosphere, leading to a large range of particle fall speeds, vapor diffusional growth rates, and aggregation efficiencies, to name a few key parameters and processes. Moreover, the parameterization of critical processes like ice nucleation remains uncertain. These uncertainties have important implications for cloud radiative forcing in particular. For example, changes in ice particle fall speed based on observed ice particle size distributions were found to have a large impact on cirrus coverage and ice water path, with large changes in cloud forcing up to $-5 \mathrm{~W} \mathrm{~m}^{-2}$ in the tropics (Mitchell et al., 2008).

The representation of ice particle properties in most current microphysics schemes is highly simplified. For example, in the Community Atmosphere Model Version 5 (CAM5, Neale et al., 2010), ice particles are represented as spheres (Morrison and Gettelman, 2008). As in nearly all bulk schemes, ice in CAM5 is separated into different categories representing small ice (cloud ice) and larger ice (snow), each with different bulk densities and fall speed-size relationships. Conversion between cloud ice and snow is parameterized by "autoconversion" that represents the growth of ice particles through vapor diffusion, aggregation, and riming. However, autoconversion has little physical basis since it does not correspond with a specific microphysical process and results in discrete transition of particle properties from cloud ice to snow. The conversion of cloud ice to snow is tuned in CAM5 by modifying the size threshold for autoconversion, $D_{\text {cs }}$.

Another issue is that there is often a lack of selfconsistency in ice particle properties in schemes. For example, nearly all bulk schemes (not only in GCMs but in finerscale models as well) have fall speed-size relationships that are not directly coupled to particle densities or mass-size relationships, leading to unphysical behavior. For example, increasing particle density can lead to a decrease in massweighted mean fall speed because this leads to a smaller mean particle size, while the fall speed-size relationship depends on mean particle size but not density. As pointed out by Mitchell et al. (2011), self-consistency among these relationships is important because of the physical coupling of these parameters. For example, the effective radius and massweighted mean fall speed are both dependent upon masssize and projected area-size relationships, so that a change in these relationships should be reflected in both the fall speed and effective radius (Mitchell et al., 2011).

Aircraft in-situ observations of ice particles provide an opportunity for detailed testing of assumptions concerning ice particle properties in microphysics schemes. While in situ observations are limited in time and space, statistical comparison with model output, especially in terms of relationships among variables, provides some constraint on microphysics schemes. Here we will investigate how well specific ice microphysical parameters are predicted and diagnosed in CAM5 as compared to in situ observations. While previous work has evaluated ice microphysics in CAM5 using aircraft observations (Zhang et al., 2013), we provide a more detailed comparison including several size distribution moments as well as mass-weighted fall speed for two different field campaigns. Focusing on several parameters is important because these quantities are closely inter-related. We then evaluate results, including cloud radiative forcing, in the context of sensitivity to the autoconversion size threshold $D_{\mathrm{cs}}-$ a key tuning parameter for radiative forcing in CAM5. A unique aspect of this study is that we compare several ice microphysical parameters with the same quantities estimated from observations. To our knowledge this has not been done previously for climate models, but is important because it allows us to dig deeper into reasons for biases in key quantities like mass-weighted fall speed.

The paper is organized as follows. In Sect. 2, the methodology of this study is presented. In Sect. 2.1 the two aircraft campaigns and associated observations that are used in this study are described, while Sect. 2.2 deals with the model setup. The microphysical parameters that are used for model - observation comparison are detailed in Sect. 2.3. The comparison results are presented in Sect. 3. Here, the results using default CAM5 parameters are first discussed in Sect. 3.1 while a sensitivity study of the ice - snow autoconversion impact on microphysical parameters is included in Sect. 3.2. Section 4 deals with cloud radiative forcing effects from the autoconversion sensitivity study. Finally, in Sect. 5, a summary and conclusions are presented.

\section{Methodology}

\subsection{Aircraft measurements}

Aircraft measurements of ice crystal size distributions from two different field campaigns are used here for the comparison with model results. These observations are from the Tropical Composition, Cloud and Climate Coupling (TC4) (Toon et al., 2010) mission in 2007 and the Atmospheric Radiation Measurements (ARM) Spring Cloud Intensive Operational Period (IOP) (e.g. Dong et al., 2002) in 2000 (hereafter called “ARM-IOP”).

The TC4 campaign was based in the tropics (Costa Rica and Panama, see Fig. 1) and one of the main science goals of 


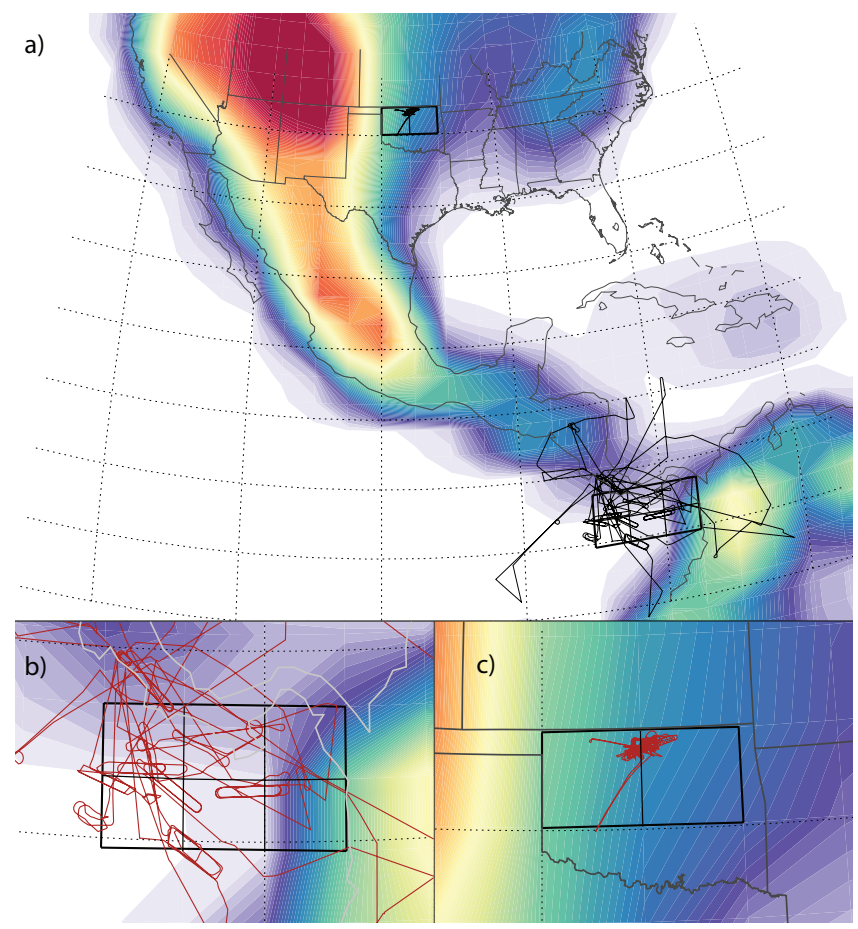

Figure 1. (a) Location of ARM-IOP and TC4, along with model grid boxes. (b) TC4 with a more detailed view of the flight tracks. (c) Same as in (b) but for ARM-IOP.

TC4 was to improve knowledge of how anvil cirrus form and evolve (Toon et al., 2010). The mostly convectively generated anvil cirrus were sampled by the NASA DC8 aircraft and the subfreezing periods had a low cloud temperature of $\sim-60{ }^{\circ} \mathrm{C}$. Particle size distributions were acquired with a Droplet Measurement Technologies (DMT) Cloud Imaging Probe (CIP) sizing from about $50-1000 \mu \mathrm{m}$ and a 2-D DMT Precipitation Imaging Probe (PIP) sizing from about $200 \mu \mathrm{m}-1 \mathrm{~cm}$. Averaging was done over $5 \mathrm{~s}$ intervals, with a total in-cloud period of about 20 hours $(\sim 15600 \mathrm{~km})$. Total condensed water content (TWC, ice plus liquid when present) was measured with a counterflow virtual impactor (CVI) for TWC $>0.01 \mathrm{gm}^{-3}$. Because of the ice shattering issue, we do not use the small particle probe data $(<75 \mu \mathrm{m})$ and modify the CIP data to account for ice shattering using particle interarrival times (see Field et al., 2006). Liquid water was detected and its content estimated from a Rosemount icing probe (RICE). Liquid water encounters were infrequent and have been filtered out of the data set. Further, data were filtered to eliminate updrafts and downdrafts above $1 \mathrm{~m} \mathrm{~s}^{-1}$, and data containing round particles larger than 1 millimeter in diameter, indicating rain or graupel, were also eliminated.

During the TC4 campaign, a 2D-S (stereo) probe was also flown on the NASA DC8 aircraft (Toon et al., 2010). This probe has a lower size detection limit and better resolution compared to the CIP. Heymsfield et al. (2014) used volume extinction coefficients $(\sigma)$ to compare 2D-S and CIP+PIP observations against a diode laser hygrometer (DLH) probe, and found that $\sigma$ from CIP+PIP compared well, while the 2D-S $\sigma$ were about $50 \%$ higher than the DLH $\sigma$. They suggested that the reason for the overestimation of 2D-S $\sigma$ was due to occasional small particles from shattering that were not removed during the post processing procedures. We therefore only use the CIP+PIP observations here.

The ARM-IOP was based in the mid-latitudes (Oklahoma, USA, see Fig. 1) and measured a variety of cloud types associated with frontal passages, convection, and synoptically generated cirrus clouds. Particle size distributions were acquired with a 2-D Cloud (2DC) probe sizing from about $50-1000 \mu \mathrm{m}$ and a 2-D Precipitation (2DP) probe. The data were acquired with the University of North Dakota Citation Aircraft. Processing was done as noted above, with averaging over $5 \mathrm{~s}$ intervals. The total in-cloud time was about $7 \mathrm{~h}$ $(\sim 3,400 \mathrm{~km})$. TWC measurements were also made with the CVI and liquid water was detected with the RICE probe. All periods of liquid water were removed from the data set, and the same filtering technique mentioned above was used.

Images from the two-dimensional probes were analyzed using maximum dimension $\left(D_{\mathrm{m}}\right)$, defined here as the diameter of the smallest circle that completely encloses the projected image. Area ratio, given by the area of the imaged particle divided by the area of the smallest enclosing circle, was used to filter poorly imaged particles from the analysis following the criteria given in Field et al. (2006). A complete discussion of these two data sets, probe evaluations, and processing methods are given in Heymsfield et al. (2013).

\subsection{Model setup}

The global model from the National Center for Atmospheric Research (NCAR) CAM5 is used in this study. The treatment of clouds in GCMs is typically divided into parameterization of convective clouds and a more detailed microphysics treatment of stratiform clouds. CAM5 includes aerosol effects and detailed microphysics only for stratiform clouds, which includes detrained mass from convective anvils. The stratiform microphysics scheme is an updated version (v1.5) of the 2-moment cloud microphysical scheme of Morrison and Gettelman (2008) and Gettelman et al. (2010). Cloud liquid and ice mass and number mixing ratios are prognosed, while rain and snow mass and number mixing ratios are diagnosed. Particle size distributions are assumed to follow gamma functions. Aerosols affect both cloud droplet and ice crystal number concentrations. The version here is noted as MG1.5, where the major change to the microphysics compared to Gettelman et al. (2010) and relevant to this study is an improvement in how nucleation of ice is applied to increase crystal number: this is now done consistently with the addition of mass from nucleation before microphysical processes are calculated within the time step.

For this study, CAM5 was run for 6 years (from 2000 trough 2005), using the first year as spin-up time and 
analyzing the last 5 years. We used the Atmosphere Model Intercomparison Program (AMIP) style configuration, with prescribed sea surface temperature (annual cycle of the sea surface temperature which repeats every year) and fixed $\mathrm{CO}_{2}$ concentrations. The resolution was $1.9 \times 2.5^{\circ}$, with 30 vertical layers, and global results were output as monthly means. However, over the model grid boxes that overlap the regions from where observations were gathered (Fig. 1), we output instantaneous microphysical parameters and state variables every $3 \mathrm{~h}$. Note that the grid boxes over the TC4 area are chosen such that they cover mainly ocean due to differences in tuning of the convective microphysics over ocean and land, which can affect radiation and detrained condensate mass feeding into the cloud microphysics. However, including grid boxes over land has a minimal impact and does not change our conclusions (not shown).

\subsection{Microphysical parameter description}

The in situ measurements give detailed information about the size distributions, masses, and projected areas of ice particles, from which mass-weighted terminal fall speeds and other parameters can be estimated. The mass-weighted terminal fall speed is an important factor in controlling lifetime of clouds, as well as controlling many other cloud parameters, since this quantity is relevant for sedimentation of ice and snow mass. For comparing the model and measurements, we will introduce a description of the size distribution parameters used here, and then describe the calculation of massweighted terminal fall speeds from the model.

\subsubsection{Size distribution parameters}

First we note that in CAM5, several output microphysical parameters are given as grid-box means rather than in-cloud values. The grid-box mean takes into account of the fraction of the grid box that contains condensate (snow and cloud ice). Here, all parameters and equations described are for in-cloud values, unless otherwise stated. In MG1.5 (as in nearly all bulk microphysics schemes), snow and cloud ice are divided into two separate categories, with both size distributions $(\phi)$ assumed to be represented by gamma functions:

$\phi(D)=N_{0} D^{\mu} e^{-\lambda D}$,

where $D$ is the particle diameter, $N_{0}$ is the intercept parameter, $\mu$ is the shape parameter and $\lambda$ is the slope parameter. Currently, the shape parameter is set to zero for both snow and cloud ice, meaning that the distributions are represented by inverse exponential functions.

We focus the comparison of modeled and observed size distribution parameters on $\lambda$ and various size distribution moments $(M)$. Herein we analyze the 0 th to 5 th moments. While number and mass concentrations are proportional to the 0th and 3rd moments in the model, other relevant parameters such as bulk projected area (relevant for collection of cloud water) and mass-weighted fall speed depend on other moments. Thus, we investigate a range of moments for comparison with observations. The $k$ th moment of the size distribution $\left(M_{k}^{*}\right)$, where $k>-1$, is found by integrating the distribution in this form:

$M_{k}^{*}=\int_{0}^{\infty} N_{0} D^{k} e^{-\lambda D} \mathrm{~d} D=\frac{N_{0} \Gamma(k+1)}{\lambda^{k+1}}$,

where $\Gamma$ is the Euler gamma function. Here the * indicates moments that are calculated from integration of the size distribution from 0 to infinity. Thus the 0th moment, which is equal to the number concentration $(N)$, can be expressed as follows:

$M_{0}^{*}=\frac{N_{0}}{\lambda}=N$.

Snow and cloud ice particles are assumed to be spherical in the model, thus the mass concentration, $q$, is proportional to the 3rd moment:

$q=\frac{\pi \rho_{\mathrm{p}}}{6} M_{3}^{*}=\frac{\pi \rho_{\mathrm{p}}}{6} \frac{N_{0} \Gamma(4)}{\lambda^{4}}=\frac{\pi \rho_{\mathrm{p}} N_{0}}{\lambda^{4}}=\frac{\pi \rho N}{\lambda^{3}}$,

where Eq. (3) is used to relate $N_{0}$ to $N$. Here, $\rho_{\mathrm{p}}$ is the bulk density of the particles. Note, however, that in situ measurements indicate that in reality the mass is closer to the 2 nd moment than the 3rd since the particles in nature are generally not spherical. An expression for $\lambda$ can be found by rearranging terms in Eq. (4):

$\lambda=\left(\frac{\pi \rho_{\mathrm{p}} N}{q}\right)^{1 / 3}$,

or by using moments:

$\lambda=\left(\frac{6 M_{0}^{*}}{M_{3}^{*}}\right)^{1 / 3}$.

Note that the size distribution parameters and moments are derived from the $q$ and $N$ after they are updated from the microphysical processes, consistent with the quantities used for the radiation calculations.

A key point is that even though cloud ice and snow are divided into separate categories in MG1.5, the size distributions for each extend from sizes of zero to infinity (i.e., a complete distribution), as in nearly all bulk microphysics schemes. Thus, we must combine the cloud ice and snow distributions to derive parameters for comparing with observations, which do not differentiate between cloud ice and snow. For $\lambda$, this is done by using $N_{\mathrm{si}}=N_{\mathrm{s}}+N_{\mathrm{i}}$ and $q_{\mathrm{si}}=q_{\mathrm{s}}+q_{\mathrm{i}}$ in Eq. (5), where the subscripts "s" and "i" stands for snow and cloud ice, respectively. For $\rho_{\mathrm{p}}$, we use a mass-weighted density $\left(\rho_{\mathrm{p}, \mathrm{si}}\right)$ that combines the snow $\left(\rho_{\mathrm{p}, \mathrm{s}}\right)$ and cloud ice $\left(\rho_{\mathrm{p}, \mathrm{i}}\right)$ particle densities, specified as 250 and $500 \mathrm{kgm}^{-3}$, respectively. However, there is an additional complication when 
calculating mass-weighted quantities because cloud ice and snow may cover different fractions of the model grid box. We therefore also take into account the grid-box snow and cloud ice fractions when mass-weighting the density. Note that in MG1.5, the fraction of snow $\left(F_{\mathrm{S}}\right)$ is, by design, always equal or greater than the fraction of cloud ice $\left(F_{\mathrm{i}}\right)$ because it is assumed that the cloud ice is a source of snow, while snow can also fall into non-cloudy parts of the grid-box from above (i.e., the maximum overlap assumption). Furthermore, this is done regardless of the snow mass mixing ratio, which could in fact be zero. The mass-weighted snow/ice particle density is therefore given by:

$\rho_{\mathrm{p}, \mathrm{si}}=\frac{F_{\mathrm{i}} \frac{\rho_{\mathrm{p}, \mathrm{i}} q_{\mathrm{i}}+\rho_{\mathrm{p}, \mathrm{s}} q_{\mathrm{s}}}{q_{\mathrm{i}}+q_{\mathrm{s}}}+\left(F_{\mathrm{s}}-F_{\mathrm{i}}\right) \rho_{\mathrm{p}, \mathrm{s}}}{F_{\mathrm{s}}}$,

where the left term in the numerator represents the part of the grid-box that contains cloud ice and snow, while the right term represent the part that only contains snow. The entire expression is then weighed by the fraction of the grid-box that snow and cloud ice covers (which, as stated above is equal to the snow fraction).

The $\lambda$ and $N_{0}$ derived from observations were calculated by linear fit in log-linear space to the measured size distributions. The fits were performed using a principal component analysis to minimize the error normal to the fit line. Only size spectra that provided at least five size bins with non-zero concentration were considered in order to maintain a reasonable fit. This threshold was generally met in this study when a measurable size distribution existed from $75 \mu \mathrm{m}$ to at least $275 \mu \mathrm{m}$ in length. When larger particles were present up to 30 bins were included in the fits. The potential fitting errors, and resulting $\lambda$ and $N_{0}$ errors, depend on the number of bins used for the fit, the number of particles measured in each size bin, and the accuracy of the instruments in a particular size range. These conditions are most favorable in broad size distributions with low $\lambda$. Due to probe inaccuracies (Strapp et al., 2001) and smaller sample volume for small particles, the errors will be larger for high $\lambda$.

For determining the moments in Eq. (2), the integration over $D$ is from zero to infinity. However, the minimum size of ice crystals considered from the observations is $75 \mu \mathrm{m}$. Therefore, for consistency the integration of the modeled moments must be done from $75 \mu \mathrm{m}$ to infinity to directly compare with the measurements:

$$
\begin{aligned}
& M_{k}=\int_{D_{\min }}^{\infty} N_{0} D^{k} e^{-\lambda D} \mathrm{~d} D \\
& =\frac{N_{0} \Gamma(k+1) \Gamma\left(k+1, D_{\min }\right)}{\lambda^{k+1}} .
\end{aligned}
$$

Here, $\Gamma\left(k+1, D_{\min }\right)$ is the incomplete gamma function. Note that in the model calculations, we still use the $q$ and $N$ consistent with integration across the entire size distribution from zero to infinity instead of from $D_{\min }$ to infinity to calculate $\lambda$ using Eq. (5). This is consistent with the $\lambda$ derived from observations, which were calculated by linear fit in loglinear space to the measured size distributions.

The measured moments $\left(M_{\mathrm{obs}, k}\right)$ are calculated using

$M_{\mathrm{obs}, k}=\sum_{D_{\min }}^{D_{\max }} N(D) D^{k}$.

where $D_{\min }$ and $D_{\max }$ is the size range of interest of the particle size distribution. Only integer moments were computed, and physical quantities may not correspond to the same moment for both the observations and model (for example, ice water content is proportional to $M_{3}$ in the model following the assumption of spherical particles but is closer to $M_{2}$ in the observations). The idea is that each moment weights a certain portion of the size distribution differently (low moments for small particles, and high moments for large ones), to allow a simple comparison with the modeled distributions. Since the measured moments are in a pure form, the observed and modeled moments can be compared directly.

\subsubsection{Mass weighted terminal fall speed}

The mass-weighted terminal fall speed is another parameter derived from observations that we will compare with model results. In CAM5, the size dependent terminal fall speed $(V)$ is expressed as a power law relation:

$V=a D^{b}$,

where $a$ and $b$ are empirical constants. In MG1.5, $a$ and $b$ have different values for ice and snow $\left(a_{\mathrm{i}}=\right.$ $700 \mathrm{~m}^{1-b} \mathrm{~s}^{-1}, b_{\mathrm{i}}=1$ following Ikawa and Saito (1991) and $a_{\mathrm{s}}=11.72 \mathrm{~m}^{1-b} \mathrm{~s}^{-1}, b_{\mathrm{s}}=0.41$ following Locatelli and Hobbs (1974)). For the comparison, we use the massweighted terminal fall speed $\left(V_{\mathrm{m}}\right)$, which is obtained by integrating the size distribution in Eq. (1), multiplied by $V$ in Eq. (10) and weighting by the mass mixing ratio. The massweighted terminal fall speed can be expressed as follows:

$$
\begin{aligned}
& V_{\mathrm{m}}=\frac{\int_{D_{\min }}^{\infty}\left(\frac{\rho_{a 0}}{\rho_{a}}\right)^{\kappa} \frac{\pi \rho_{\mathrm{p}}}{6} a D^{b+3} \phi(D) \mathrm{d} D}{\int_{D_{\min }}^{\infty} \frac{\pi \rho_{\mathrm{p}}}{6} D^{3} \phi(D) \mathrm{d} D} \\
& =\frac{\left(\frac{\rho_{a 0}}{\rho_{a}}\right)^{\kappa} \frac{a \Gamma(b+4) \Gamma\left(b+4, D_{\min }\right)}{\lambda^{b+4}}}{\frac{\Gamma(4) \Gamma\left(4, D_{\min }\right)}{\lambda^{4}}} \\
& =\left(\frac{\rho_{a 0}}{\rho_{a}}\right)^{\kappa} \frac{a \Gamma(b+4) \Gamma\left(b+4, D_{\min }\right)}{6 \lambda^{b} \Gamma\left(4, D_{\min }\right)} .
\end{aligned}
$$

Here, $\rho_{a}$ is the air density, and $\rho_{a 0}$ is typical air density at $850 \mathrm{mb}$, which is an air density factor based on Heymsfield et al. (2007). For ice, $\kappa=0.35$ (Ikawa and Saito, 1991) and for snow, $\kappa=0.54$ (Heymsfield et al., 2007). Relating $V_{\mathrm{m}}$ to the size distribution moments, for cloud ice, $V_{\mathrm{m}}$ is proportional to $M_{4} / M_{3}$ while for snow $V_{\mathrm{m}}$ is proportional to $M_{3.41} / M_{3}$. 
Since the snow and cloud ice categories are not distinguished in the observations, the modeled snow and cloud ice $V_{\mathrm{m}}$ need to be combined into $V_{\mathrm{m}, \mathrm{si}}$ in order to compare with observations. We follow the same formulation as for the mass-weighted particle density (Eq. 7):

$V_{\mathrm{m}, \mathrm{si}}=\frac{F_{\mathrm{i}} \frac{V_{\mathrm{m}, \mathrm{i}} q_{\mathrm{i}}+V_{\mathrm{m}, \mathrm{s}} q_{\mathrm{s}}}{q_{\mathrm{i}}+q_{\mathrm{s}}}+\left(F_{\mathrm{s}}-F_{\mathrm{i}}\right) V_{\mathrm{m}, \mathrm{s}}}{F_{\mathrm{s}}}$,

where $V_{\mathrm{m}, \mathrm{s}}$ and $V_{\mathrm{m}, \mathrm{i}}$ are the snow and cloud ice massweighed terminal fall speed respectively.

The mass-weighted fall speeds from the in-situ observations were computed using the Reynolds number-Best number approach approach described in Heymsfield and Westbrook (2010). They included the area ratio of the particles (area of the particle's projected area to the area of a circumscribing disk) when determining the mass-weighted fall speeds. The projected area is measured directly with the CIP ( $25 \mu \mathrm{m}$ resolution) in TC4 and the $2 \mathrm{DC}(30 \mu \mathrm{m}$ resolution) in the ARM-IOP project. Mass is computed from the powerlaw relationship $m=0.00528 D^{2.1}$ given in Heymsfield et al. (2010), which when integrated gave generally good agreement with the total mass measured by the CVI.

\subsubsection{Critical Diameter for ice snow autoconversion}

In MG1.5, the conversion of cloud ice to snow via "autoconversion" is treated by transferring mass and number mixing ratio from condensate (cloud ice) to precipitation (snow) based on the critical size threshold, $D_{\mathrm{cs}}$ and an assumed conversion timescale (Morrison and Gettelman, 2008). Expressions for the grid-box mean tendencies are as follows:

$$
\begin{aligned}
& \left(\frac{\partial q_{\mathrm{i}}^{\prime}}{\partial t}\right)_{\text {auto }}= \\
& -F_{\mathrm{i}} \frac{\pi \rho_{\mathrm{i}} N_{0 i}}{6 \tau_{\text {auto }}}\left[\frac{D_{\mathrm{cs}}^{3}}{\lambda_{\mathrm{i}}}+\frac{3 D_{\mathrm{cs}}^{2}}{\lambda_{\mathrm{i}}^{2}}+\frac{6 D_{\mathrm{cs}}}{\lambda_{\mathrm{i}}^{3}}+\frac{6}{\lambda_{\mathrm{i}}^{4}}\right] e^{-\lambda_{\mathrm{i}} D_{\mathrm{cs}}} \\
& \left(\frac{\partial N_{\mathrm{i}}^{\prime}}{\partial t}\right)_{\text {auto }}=-F_{\mathrm{i}} \frac{N_{0 i}}{\lambda_{\mathrm{i}} \tau_{\text {auto }}} e^{-\lambda_{\mathrm{i}} D_{\mathrm{cs}}}
\end{aligned}
$$

(Morrison and Gettelman, 2008). Here $\tau_{\text {auto }}=3 \mathrm{~min}$ is the assumed autoconversion time scale. The quantities with a prime denote the grid-box average values. Since cloud ice and snow have much different particle densities and terminal fall speed parameters (as described in Sects. 2.3.1 and 2.3.2), there is a discontinuity of bulk ice properties after conversion from cloud ice to snow. Although $D_{\mathrm{cs}}$ is a size parameter for conversion of cloud ice to snow, not all particles larger than $D_{\mathrm{cs}}$ are classified as snow since the cloud ice distribution is complete (meaning that it extends from zero to infinity with significant concentrations larger than $D_{\mathrm{cs}}$ ). The parameter $D_{\mathrm{cs}}$ is chosen rather arbitrary and is one of the main tuning parameters in CAM5: for a given $N_{\mathrm{i}}$, a larger value
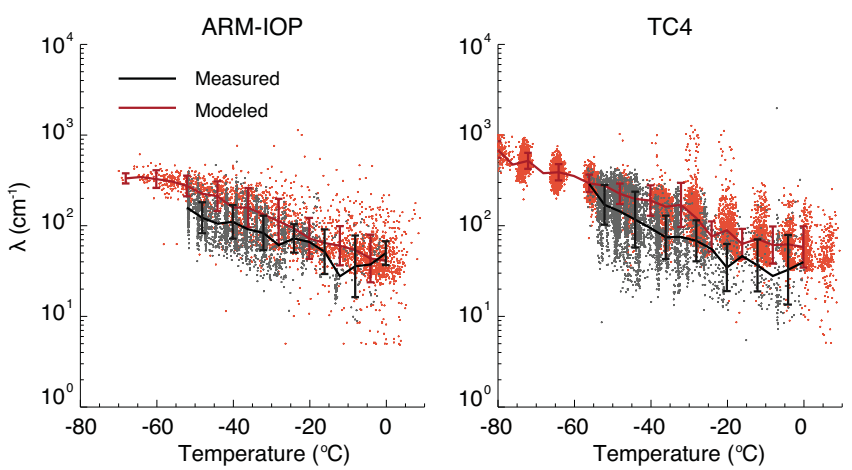

Figure 2. Slope parameter, modeled (red) and measured (black) for ARM-IOP and TC4. The lines are the geometric mean, the dots represents a fraction of the measurements and modeled values, while the vertical bars represents the geometric standard deviation.

for $D_{\mathrm{cs}}$ allows higher cloud ice water content before conversion to snow. The default value for $D_{\mathrm{cs}}$ in MG1.5 is $250 \mu \mathrm{m}$ but we will also show results with $D_{\mathrm{cs}}=80,100,150,400$ and $500 \mu \mathrm{m}$ in Sect. 3.2, which is similar to the range of $D_{\mathrm{cs}}$ tested by Zhao et al. (2013). However, we first describe comparison of the model and observations using the default value of $D_{\mathrm{cs}}$ in Sect. 3.1.

\section{Results}

\subsection{Control model - observations comparison $\left(D_{\mathrm{cs}}=250 \mu \mathrm{m}\right)$}

The measurements were collected mainly in cirrus clouds, but the formation mechanisms generally differed between the TC4 and ARM-IOP cases (Heymsfield et al., 2013). The cirrus in TC4 were mainly anvils associated with deep convection while the cirrus from the ARM-IOP were in situgenerated. We therefore expect to see some differences in the modeled parameters between the two locations, as also seen in the observations (Heymsfield et al., 2013). First we compare the slope parameter $\lambda$ between model and measurements.

\subsubsection{Slope parameter}

Figure 2 shows the modeled (red) and measured (black) $\lambda$ as a function of temperature (which is nearly analogous to height). The solid lines are the geometric mean of the measured or modeled $\lambda$. The modeled $\lambda$ is about a factor of 2 higher than the observed across the entire range of temperatures analyzed. As shown below, this difference between the model results and observations is consistent with both an over-prediction of number concentration of particles larger than $75 \mu \mathrm{m}\left(N_{75}\right.$ or $\left.M_{0}\right)$ and under-prediction of $M_{3}$.

The change in $\lambda$ as a function of temperature, however, is fairly similar between model and observations. By fitting 

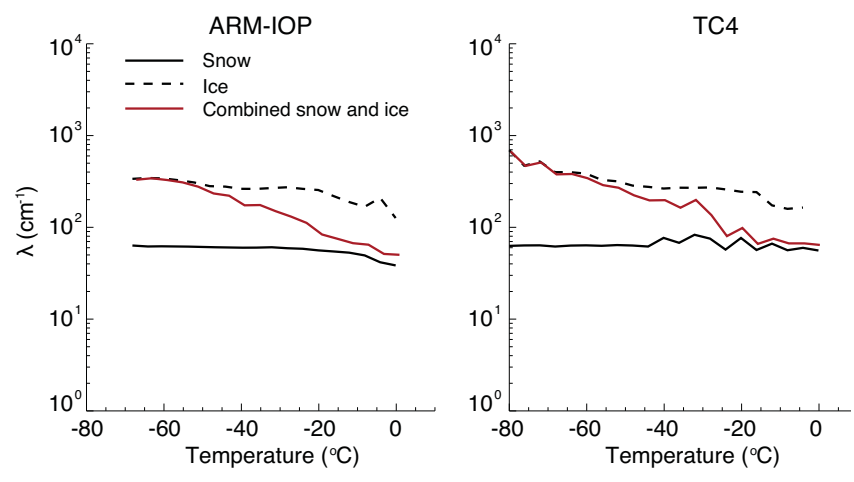

Figure 3. Modeled slope parameter, for ice and snow individually. Also shown is the combined snow and ice slope parameter, as shown in Fig. 2.

the data to the exponential equation $\lambda=A e^{-B T}$, the $B$ coefficient for modeled and measured fitted data for ARM-IOP are, respectively, -0.028 and -0.025 , while for TC4 they are -0.03 and -0.032 . Note that in Heymsfield et al. (2013), the $B$ coefficient determined for TC 4 is -0.0868 . In their paper, the size distribution shape parameter $(\mu)$ is not assumed to be zero, as we assume in this study. A non-zero $\mu$ results in a steeper $\lambda-T$ relationship and hence $B$ decreases (becomes more negative). For the ARM-IOP case, Heymsfield et al. (2013) found the $B$ coefficient to be -0.0292 , which is comparable with our model results.

The reason that $\lambda$ decreases with increasing temperature in the model is mainly due to the change in the ratio of snow to cloud ice mass as temperature increases (or as height decreases). Figure 3 shows that when the modeled $\lambda$ is calculated individually for snow $\left(\lambda_{\mathrm{s}}\right)$ and cloud ice $\left(\lambda_{\mathrm{i}}\right), \lambda_{\mathrm{s}}$ is fairly constant over all temperatures. Further, $\lambda_{\mathrm{i}}$ is larger than $\lambda_{\mathrm{s}}$, and larger lambda values shifts the size distribution to smaller sizes. When considering Figs. 2 and 3, it is clear that cloud ice mass dominates at low temperatures $\left(<-50^{\circ} \mathrm{C}\right)$, while snow mass dominates at relatively higher temperatures ( $>-20^{\circ} \mathrm{C}$ ); the combined $\lambda$ is closer to $\lambda_{\mathrm{i}}$ at low temperatures and closer to $\lambda_{\mathrm{s}}$ at warmer temperatures. This is partly explained by the limited amount of vapor available for growing ice particles at lower temperatures. In addition, more ice particles are typically nucleated at low temperatures, and there is more competition for the available vapor. Thus, mean particle size tends to be smaller at low temperatures, and conversion from cloud ice to snow is limited.

\subsubsection{Moments}

Figures 4 and 5 show the moments for ARM-IOP and TC4, respectively. Recall that the zero moment $\left(M_{0}\right)$ is the same as the number concentration of particles larger than $75 \mu \mathrm{m}$, $N_{75}$. For ARM-IOP (Fig. 4), $M_{0}$ is overestimated by about a factor of 2 between -35 and $-10^{\circ} \mathrm{C}$, while at temperatures lower than $-40{ }^{\circ} \mathrm{C}$ the model underestimates com- pared to the measurements. For deposition ice nucleation in CAM5, the parameterization by Meyers et al. (1992) is used at temperatures $>-37^{\circ} \mathrm{C}$ (but with constant freezing rate at temperatures $<-20^{\circ} \mathrm{C}$ ). It has been shown in several papers that this parameterization will typically over-predict ice nucleation by at least an order of magnitude (e.g. Prenni et al., 2007; DeMott et al., 2010). Here the differences in number concentration are much smaller and the assumption of holding the freezing rate constant for deposition nucleation at temperatures $<-20^{\circ} \mathrm{C}$ seems to improve prediction of ice nucleation at temperatures warmer than $-40^{\circ} \mathrm{C}$. At lower temperatures $\left(<-40^{\circ} \mathrm{C}\right)$, the ice nucleation scheme in CAM5 allows for competition between heterogeneous and homogeneous freezing of deliquescence aerosols (Liu and Penner, 2005). In this scheme, heterogeneous ice nucleation occurs in the form of immersion freezing of dust, and is based upon classical nucleation theory. In certain cases, for in situ generated cirrus, heterogeneous ice nucleation on a few aerosols will start at lower ice saturation than for homogeneous freezing of deliquescence aerosols (e.g. DeMott et al., 1997; Gierens, 2003). These newly formed ice crystals can rapidly deplete the vapor by vapor diffusion, limiting homogeneous aerosol freezing and leading to small ice crystal concentration. If, on the other hand, the number of heterogeneous frozen ice crystals is small enough, homogeneous freezing can still occur and the resulting ice crystal concentration can be fairly high (e.g. Barahona et al., 2009; Eidhammer et al., 2009). It is possible that the prediction of ice crystals from heterogeneous nucleation is too high at lower temperatures, where the classical nucleation theory for immersion freezing is used (e.g. Zhang et al., 2013; Eidhammer et al., 2009). This may be why we see an underestimation of $M_{0}$ at temperatures below $-40^{\circ} \mathrm{C}$ because the competition between heterogeneous and homogeneous nucleation leads to suppression of homogeneous freezing of deliquescence aerosols. Zhang et al. (2013) came to a similar conclusion in their study with CAM5.

The measurements only go down to $-55^{\circ} \mathrm{C}$, thus we cannot say how well the model performs at lower temperatures. For $M_{0}$ at temperatures between -10 and $-35^{\circ} \mathrm{C}$, both the model and observations show a decrease in $M_{0}$ as a function of temperature. The modeled $M_{0}$ show a slightly smaller decrease with increasing temperature compared to the observations. The aggregation efficiency specified in the model is rather low (0.1), compared to some estimates at warmer temperatures (near freezing, in conditions with a quasi-liquid layer), or in the dendritic growth regime near -13 to $-15^{\circ} \mathrm{C}$ (Pruppacher and Klett, 1997). This could result in a smaller decrease in $M_{0}$ with temperature. However, the ice nucleation rate in CAM could also be a source of the large modeled $M_{0}$ values. It is not possible based on current observational data to isolate the cause of this bias.

The first moment $\left(M_{1}\right)$, which represents the total integrated particle size of the snow and cloud ice population of particles larger than $75 \mu \mathrm{m}$, has similar trends to $M_{0}$ for 

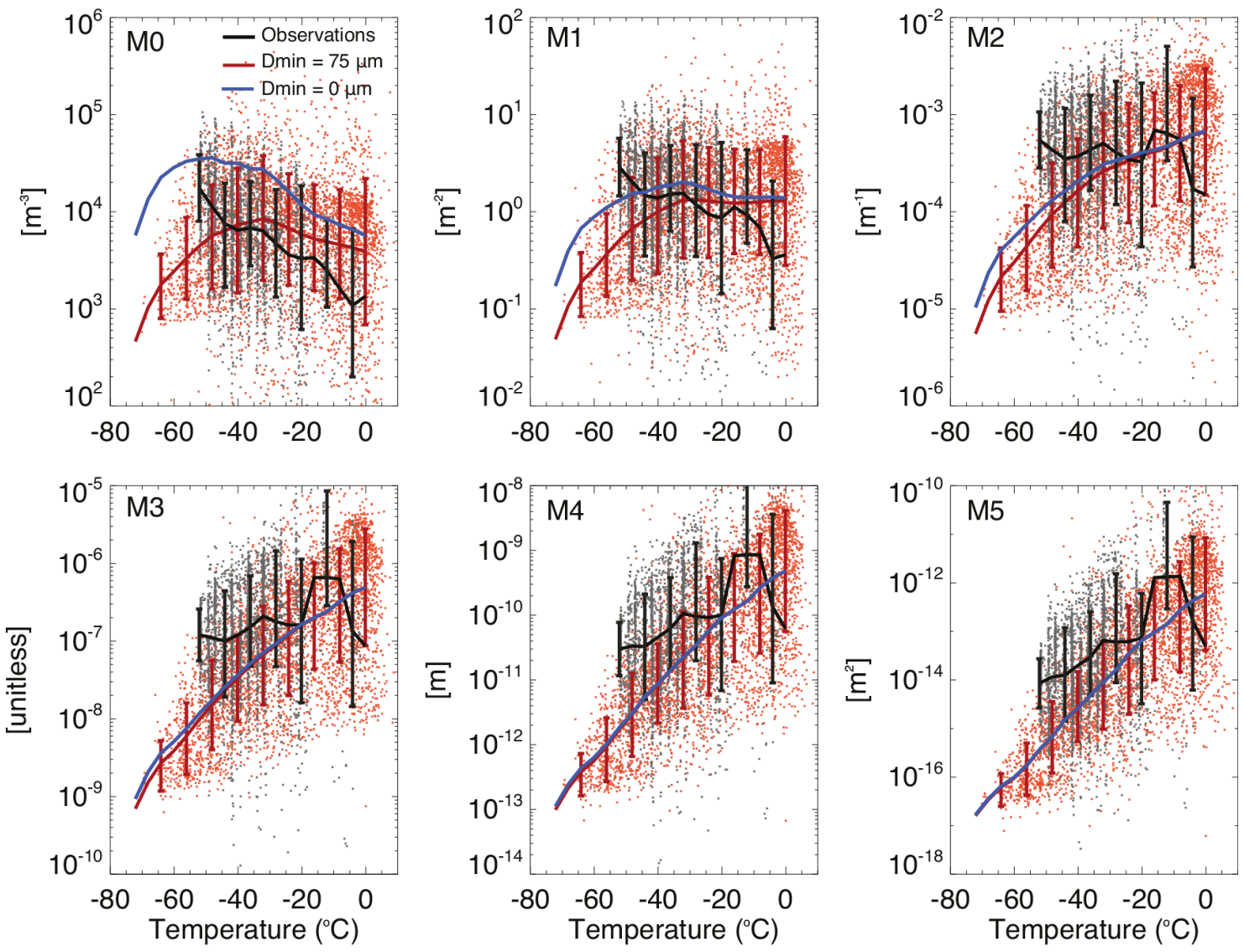

Figure 4. Moments from ARM-IOP (black: measurements. red: model integrated from $75 \mu \mathrm{m}$, blue: model integrated from $0 \mu \mathrm{m})$. Lines are geometric mean, dots represents a fraction of the measurements and model results, while vertical lines are the geometric standard deviation.

ARM-IOP (Fig. 4), with overestimation at higher temperatures $\left(T>-30^{\circ} \mathrm{C}\right)$ and underestimation at lower temperatures. For the higher moments, $M_{2}$ shows a reasonable agreement at temperatures between -25 and $-10^{\circ} \mathrm{C}$, while there is still an underestimation at lower temperatures. For $M_{3}$, $M_{4}$, and $M_{5}$, the model underestimates values over almost the entire temperature regime, while the trend with temperature is in slightly better agreement than for the smaller moments. An underestimation of the higher moments by the model indicates that the concentration of large particles is too low. This could be due to uncertainties in several microphysical processes and parameters including the rather low aggregation efficiency or too slow diffusional growth.

When considering the TC4 moments (Fig. 5), the modeled $M_{0}$ in general compares better with observations than for ARM-IOP. However, the model still overestimates $M_{0}$, with about a factor of 1.5 over-prediction for temperatures less than $-10^{\circ} \mathrm{C}$. Note that although the observations and model results for TC4 considered here are of stratiform cloud types (anvil cirrus), detrainment plays an important role. The source of the ice crystal number concentration of the detrained condensate comes from an assumed particle radius ( $25 \mu \mathrm{m}$ for deep convection and $50 \mu \mathrm{m}$ for shallow convec- tion) and therefore the model does not explicitly calculate ice nucleation from the detrained ice. The slope of $M_{0}$ with temperature is again fairly similar between the model and observations. The first moment $\left(M_{1}\right)$ shows a remarkably close agreement between observations and model. However, when considering the higher moments $\left(M_{2}, M_{3}, M_{4}\right.$ and $\left.M_{5}\right)$, the model tends to have lower values compared to observations. Again, the rate of change of the moments with temperature is about the same between the model and observations at temperatures less than $-10^{\circ} \mathrm{C}$. Interestingly, both the model and observations show a slight increase in $M_{4}$ and $M_{5}$ at around $-30^{\circ} \mathrm{C}$. Overall, the TC4 model results are in better agreements with observations than for the ARM-IOP case.

For the moments, we have only considered particles larger than $75 \mu \mathrm{m}$. For comparison Figs. 4 and 5 also show the moments for the ARM-IOP and TC4 cases from the model when integrating the moments from either $0 \mu \mathrm{m}$ or $75 \mu \mathrm{m}$. Clearly the lower moments increase when including all sizes, while the higher moments are not as sensitive to inclusion of small sizes in the integration.

The moment comparison gives an illustration of the behavior of the modeled and observed size distributions. However, this comparison does not reveal differences in ice (cloud 

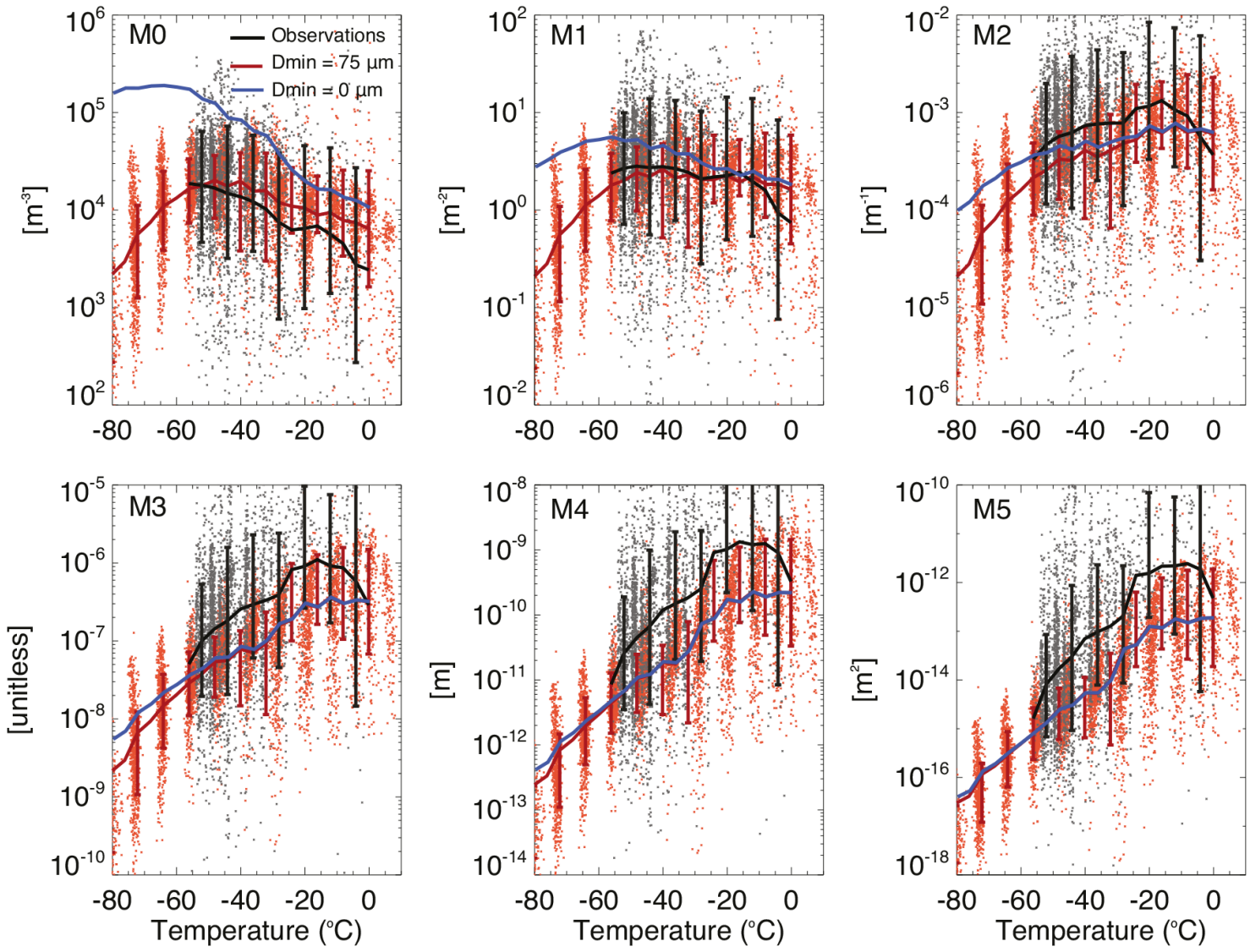

Figure 5. Same as Fig. 4, but for TC4.
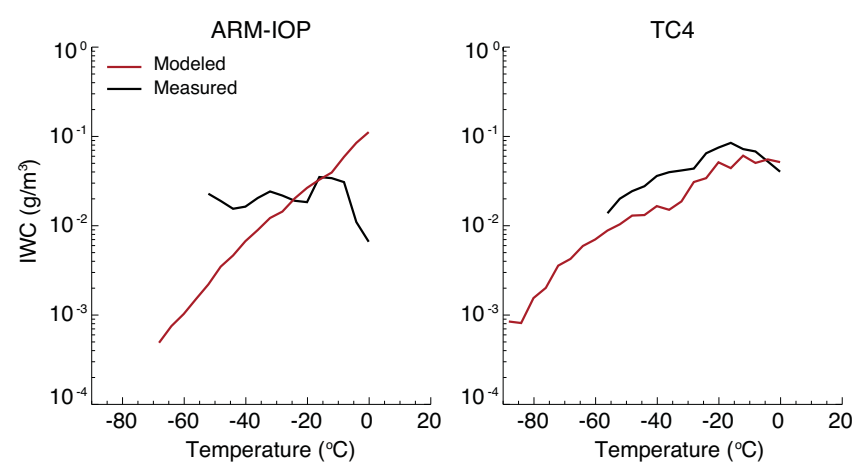

model and observation have a similar temperature trend but the modeled IWC is slightly lower than the observed IWC.

\subsubsection{Mass-weighted terminal fall speed}

Figure 7 shows the mass-weighted terminal fall speeds $\left(V_{\mathrm{m}}\right)$, where Fig. 7a compares $V_{\mathrm{m}}$ from the model and observations for both TC4 and ARM-IOP and Fig. 7b (TC4) and c (ARMIOP) are included to show the spread of $V_{\mathrm{m}}$ for the model and observations. In general, $V_{\mathrm{m}}$ determined from the model are somewhat lower than the $V_{\mathrm{m}}$ derived from the measurements. Furthermore, TC4 tends to have higher $V_{\mathrm{m}}$ than ARM-IOP, and this is seen in both the model and observations. The $V_{\mathrm{m}}$ at temperatures above $-25^{\circ} \mathrm{C}\left(-20^{\circ} \mathrm{C}\right)$ increase sharply in the TC4 (ARM-IOP) observations, while the modeled $V_{\mathrm{m}}$ show less variation with temperature in this region. However, note that there are very few measurements at temperatures above about $-20^{\circ} \mathrm{C}$ for ARM-IOP and TC4. At lower temperatures $\left(<-25^{\circ} \mathrm{C}\right)$, the $V_{\mathrm{m}}$ derived from observations are about a factor of 1.2 higher in the TC4 case compared to the model, but the trend of modeled $V_{\mathrm{m}}$ with temperature is in reasonable agreement with observations. There is less variation of $V_{\mathrm{m}}$ with temperature for the ARM-IOP observations compared to TC4, which is not captured by the model. The

ice + snow) water content (IWC) since IWC in the model is proportional to $M_{3}$ (assumed spherical shape) while the observed IWC is proportional closer to $M_{2}$. Therefore we also show a comparison of the IWC (Fig. 6). The observed IWC from ARM-IOP is rather insensitive to temperature, while the modeled IWC has a sharp increase with temperature, with smaller than observed values at low temperatures and larger values at relatively high temperatures. For the TC4 IWC, the 

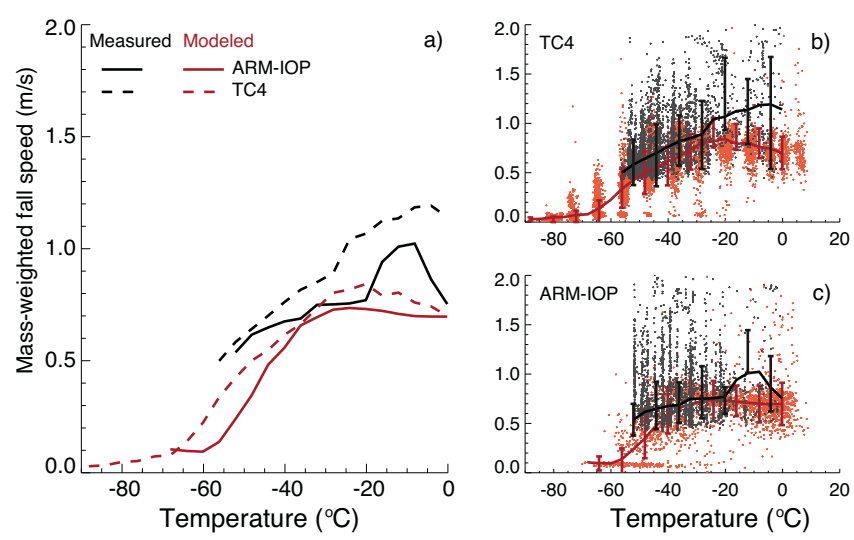

Figure 7. Mass-weighted terminal fall speed. (a) Measured and modeled $V_{\mathrm{m}}$ for ARM-IOP and TC4 for comparing fall speeds between campaigns. (b) and (c) Mass weighted fall speeds for showing the measurement and modeling spread.

increase of $V_{\mathrm{m}}$ with temperature in the model mostly reflects an increase in the ratio of snow to cloud ice, since $V_{\mathrm{m}}$ is inversely proportional to $\lambda$ while $\lambda$ does not vary much with temperature for cloud ice and snow individually (see Fig. 3). Thus, the trend of $V_{\mathrm{m}}$ with temperature in the model is mostly controlled by conversion of cloud ice to snow, which influences the mass densities and fall speeds. As described in Sect. 3.2, this conversion has a limited physical basis. Further, the physical reason for the general increase of $V_{\mathrm{m}}$ with temperature in the model is the increase of mean particle size (combined cloud ice and snow) with temperature, consistent with the change in $\lambda$ with temperature (see Fig. 2). As can be seen in the model, $V_{\mathrm{m}}$ at temperatures less than $-60^{\circ} \mathrm{C}$ is smaller than $0.3 \mathrm{~m} \mathrm{~s}^{-1}$ and small ice dominates in this region.

In general, smaller modeled $V_{\mathrm{m}}$ compared to observations is expected since $V_{\mathrm{m}}$ is inversely proportional to $\lambda$ (see Eq. 11). Since the modeled $\lambda$ is larger than measured (see Fig. 2), the modeled $V_{\mathrm{m}}$ should be smaller than those derived from measurements. To illustrate the effect the factor of 2 in bias for $\lambda$ has on $V_{\mathrm{m}}$, we calculated $V_{\mathrm{m}}$, assuming snow and cloud ice $\lambda=\lambda / 2$ (Fig. 8, blue curves). Where snow dominates the total ice mass results are now closer to observations, but where cloud ice is prevalent the $V_{\mathrm{m}}$ are still lower in the model than the observations.

The modeled $V_{\mathrm{m}}$ are not only dependent on $\lambda$, but also on the assumed power law fall speed-size parameters for cloud ice and snow in Eq. (10). To test the sensitivity to these parameters, we ran a simulation with $a_{\mathrm{i}}$ and $a_{\mathrm{s}}$ increased by $50 \%$. These results are also shown in Fig. 8 (green curves). At lower temperatures, where cloud ice dominates the total ice mass, $V_{\mathrm{m}}$ does not change much. However, at higher temperatures where snow contributes more significantly to the total mass, $V_{\mathrm{m}}$ increases by about $50 \%$. This is seen in both the ARM-IOP and TC4 cases. For the ARM-IOP case, the increase in $a$ is clearly too large compared to observations, but for the TC4 case, the comparison between model and
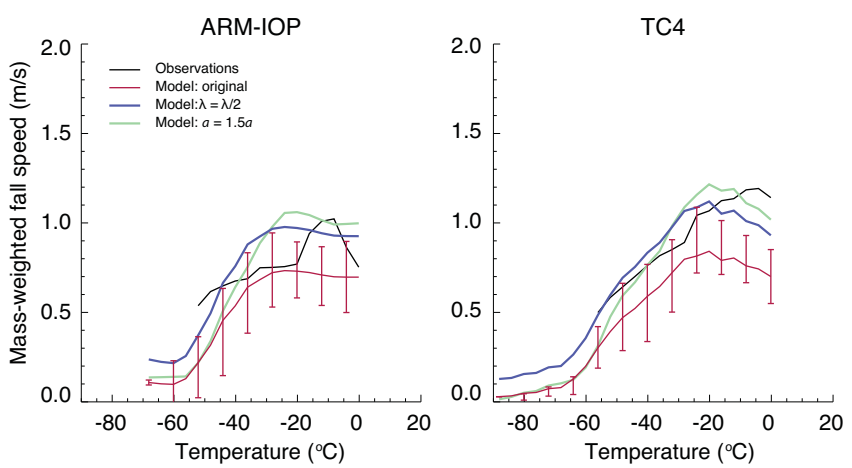

Figure 8. Mass-weighted terminal fall speed with snow and cloud ice $\lambda=\lambda / 2$ (blue), and $a_{\mathrm{i}}$ and $a_{\mathrm{s}}$ increased with $50 \%$ (green).

observations improves (but still has values somewhat larger than those from observations). This may reflect differences in fall speed parameters between in situ and anvil cirrus as suggested by observations (Heymsfield et al., 2013). However, the increased $a$ parameter in the simulations probably compensates for the over-prediction of $\lambda$. Thus, this result does not suggest that $a$ should be increased by up to $50 \%$ to obtain better agreement with observations. Rather, it suggests the importance of accurately predicting $\lambda$ specifying realistic values of the fall speed parameters.

\subsection{Cloud ice to snow autoconversion sensitivity tests}

As shown in Sect. 3.1, the model does a reasonable job in predicting some of the size distribution parameters and aspects of the mass-weighted terminal fall speed. However, there are still clear discrepancies between model results and observations. Moreover, the trends of $\lambda, V_{\mathrm{m}}$, and the size distribution moments with temperature in the model are mainly controlled by the partitioning of cloud ice and snow, which is primarily determined by cloud ice to snow autoconversion but has limited physical basis as described below.

The critical size for autoconversion of cloud ice to snow, $D_{\mathrm{cs}}$, is one of the major tuning parameters in CAM5. For example, Zhao et al. (2013) found that among 16 parameters in CAM5, the top of atmosphere radiative forcing responded most efficiently to the tuning of $D_{\mathrm{cs}}$ (changes in cloud ice and snow fall speed parameters and the lower limit on cloud droplet number had smaller impact). When cloud ice is converted to snow, mass and number mixing ratios are moved from one category to another, with discrete changes to particle density and the fall speed parameters. Cloud ice to snow autoconversion has a limited physical basis since it does not represent a specific microphysical process, and hence the "best" value for $D_{\mathrm{cs}}$ is not well established empirically or theoretically. If it is tuned to make the model results comparable with observed cloud radiative forcing, the calculation of other important microphysical parameters might be degraded (Zhang et al., 2013). For example, Zhang et al. (2013) 

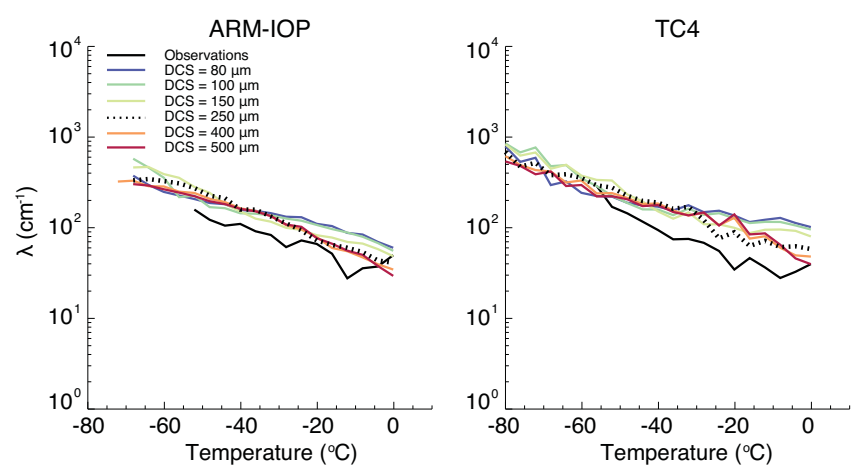

Figure 9. Same as Fig. 2, but with simulations using different $D_{\mathrm{cs}}$ values.

found that using $D_{\mathrm{cs}}=250 \mu \mathrm{m}$ led to close agreement with observations from the SPARTICUS (Small Particles in Cirrus) campaign for the effective particle size, while the total cloud radiative forcing (shortwave + longwave) at the top of the atmosphere was closer to observations when using higher $D_{\text {cs }}$ values. However, as shown in Sect. 3.1, several microphysical parameters that we compared showed rather poor agreement using $D_{\mathrm{cs}}=250 \mu \mathrm{m}$. Here we compare the same parameters as above, but across a range of settings for $D_{\mathrm{cs}}$.

We conducted 5 additional simulations with $D_{\mathrm{cs}}=80$, $100,150,400$ and $500 \mu \mathrm{m}$. We chose a rather wide span of $D_{\mathrm{cs}}$ settings since this parameter is not constrained physically. The range of values tested here is similar to Zhao et al. (2013) $(100-500 \mu \mathrm{m})$ and larger than in Zhang et al. (2013) (175-325 $\mu \mathrm{m})$ and Gettelman et al. (2010) (150$250 \mu \mathrm{m})$. Figure 9 shows $\lambda$ for all the different $D_{\mathrm{cs}}$ values. Overall, none of the values of $D_{\text {cs }}$ tested improves the comparison with observation, and hence $\lambda$ is still too large in the model. The differences between the various runs are not monotonic with changes in $D_{\mathrm{cs}}$ and do not show a clear trend with temperature (at some temperatures they are higher than the control run, at some temperatures they are lower, regardless if $D_{\mathrm{cs}}$ is higher or lower than in the control run).

Figures 10 and 11 show the moments for ARM-IOP and TC4, respectively. For $M_{0}$ in the ARM-IOP case there is a clear increase with smaller $D_{\mathrm{cs}}$ values. When $D_{\mathrm{cs}}$ is increased, there is only a change in $M_{0}$ at the highest temperatures (above $-20^{\circ} \mathrm{C}$ ). None of the various $D_{\mathrm{cs}}$ simulations significantly improve $M_{0}$ compared to measurements. For $M_{1}$, the higher values of $D_{\mathrm{cs}}$ improve the comparison slightly at temperatures above about $-30^{\circ} \mathrm{C}$. For larger moments the simulations are similar at higher temperatures, but there are some differences at lower temperatures. $D_{\mathrm{cs}}=80 \mu \mathrm{m}$ compares slightly better at low temperatures for $M_{1}, M_{2}$ and $M_{3}$, but overall, the moment comparison with observations does not notably improve by varying $D_{\mathrm{cs}}$ for the ARM-IOP case.

When considering the moments for TC4, the trend of $M_{0}$ with temperature shows a slightly different picture than in the ARM-IOP case. Simulations with large $D_{\text {cs }}$ produce the largest $M_{0}$ at low temperatures. However, this trend reverses at higher temperatures, so that simulations with small $D_{\mathrm{cs}}$ have the largest $M_{0}$. Nonetheless, the trend in $M_{0}$ with temperature still compares best with measurements when using $D_{\mathrm{cs}}=250 \mu \mathrm{m}$. For $M_{1}$, the $D_{\mathrm{cs}}=250 \mu \mathrm{m}$ simulation also compares best with measurements, while for the higher moments, the sensitivity to $D_{\mathrm{cs}}$ cases is smaller, with all simulations exhibiting bias compared to observations.

It is clear that changes in $D_{\mathrm{cs}}$ have a large impact on the mass-weighted terminal fall speed $V_{\mathrm{m}}$ (Fig. 12). When cloud ice is converted to snow at relatively small sizes $\left(D_{\mathrm{cs}}=\right.$ $80 \mu \mathrm{m}), V_{\mathrm{m}}$ is almost the same at all temperatures. This is because the particles are mainly snow, and the slope parameter $\lambda$ for snow is almost constant in this case (see Fig. 3, and note that the $D_{\mathrm{cs}}=80 \mu \mathrm{m}$ case has a similar temperature trend for snow, only with somewhat higher values).

When the conversion from cloud ice to snow occurs at larger sizes $\left(D_{\mathrm{cs}}>400 \mu \mathrm{m}\right), V_{\mathrm{m}}$ is small at low temperatures, and only increases to larger values at temperatures above about $-50^{\circ} \mathrm{C}$. At higher temperatures $V_{\mathrm{m}}$ is largest with $D_{\text {cs }}=500 \mu \mathrm{m}$. This occurs because conversion from cloud ice to snow is delayed when $D_{\text {cs }}$ is large, so that the mean particle size and hence $V_{\mathrm{m}}$ are relatively large once cloud ice is converted to snow. The higher $D_{\mathrm{cs}}$ simulations have a comparable temperature trend for TC4, but $V_{\mathrm{m}}$ are still too low compared to observations. In summary, none of the values of $D_{\text {cs }}$ gives a clearly improved comparison with observations for the parameters analyzed here.

\section{Sensitivity of cloud radiative forcing to $D_{\mathrm{cs}}$}

In the previous section we showed that changing $D_{\mathrm{cs}}$ has a large impact on the mass-weighted terminal fall speed and the smaller moments in the size distribution. As changes in $D_{\mathrm{cs}}$ impact $V_{\mathrm{m}}$ and other processes (such as BergeronFindeisen-Wegener process, i.e. the conversion of liquid to ice through ice depositional growth), the liquid and ice water paths change as well as the effective radii. These changes in turn impact the cloud radiative forcing consistent with previous studies (Gettelman et al., 2010; Zhang et al., 2013; Zhao et al., 2013). These studies used MG microphysics in CAM5 and showed that, globally, it is the longwave cloud forcing that is most influenced by changes to $D_{\mathrm{cs}}$. Gettelman et al. (2010) and Zhao et al. (2013) also showed that the changes in total cloud forcing (longwave plus shortwave) varies in magnitude as a function of latitude, with the mid-latitudes experiencing the largest changes in terms of sensitivity to $D_{\text {cs }}$. Moreover, as previously stated, Zhang et al. (2013) found that among 16 different parameters, changes to $D_{\mathrm{cs}}$ had the largest impact on top of the atmosphere radiation. In our simulations, with regard to changes to $D_{\mathrm{cs}}$, we come to some of the same conclusions. Here we also show which microphysical variables have the most impact on the cloud radiative forcing through changes in $D_{\mathrm{cs}}$. 

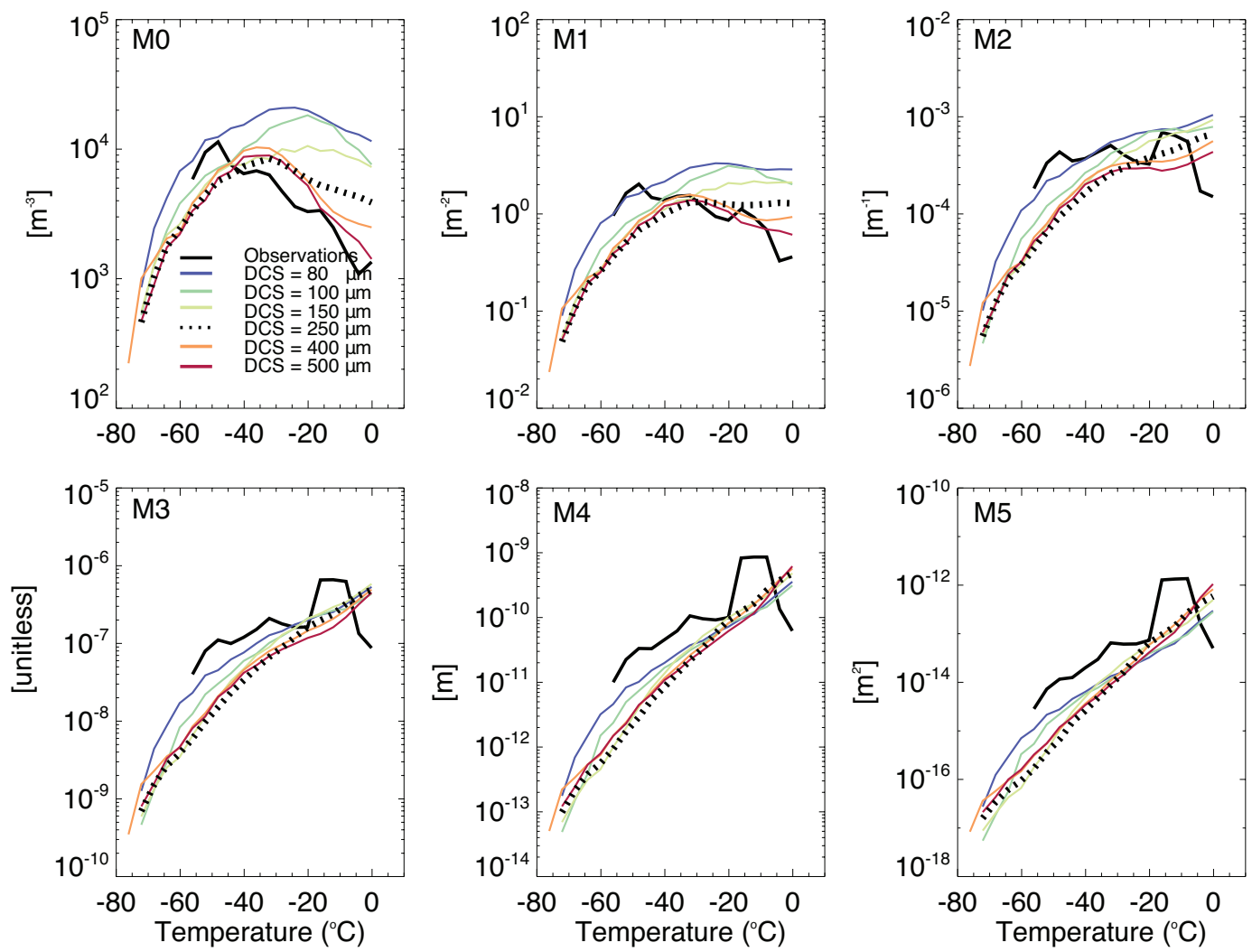

Figure 10. Same as Fig. 4, (ARM-IOP) but with various $D_{\mathrm{cs}}$ values.

Figure 13 shows how the zonally averaged shortwave and longwave radiative cloud forcing (SWCF and LWCF respectively) is affected by changes to $D_{\mathrm{cs}}$ as a function of latitude. The LWCF has an increase with increasing $D_{\mathrm{cs}}$ over all latitudes, while the SWCF has opposite effects between mid-latitudes and tropics. The cloud radiative forcing is dependent upon the ice and snow effective radii (proportional to $M_{3} / M_{2}$ ) as well as ice and snow water contents (proportional to $M_{3}$ in the model), in addition to cloud droplet effective radius and cloud liquid water content. To investigate which quantities are the major controlling factors in the sensitivity of cloud radiative forcing to $D_{\mathrm{cs}}$, we plot several key zonally averaged quantities in Fig. 14. Figure 14a, b, c and $\mathrm{d}$ shows the combined cloud ice plus snow water path, cloud liquid water path, snow water path and cloud ice water path, respectively (note that the water path is the vertical integral of the water content). Figure 14e shows the effective radii of cloud ice and snow, while Fig. 14f shows the effective radius of cloud droplets.

As $D_{\mathrm{cs}}$ increases, less cloud ice is converted to the snow category monotonically as is shown in Fig. $14 \mathrm{c}$ and d at mid-latitudes. There is limited impact on the total cloud ice plus snow water path in the mid latitudes since changes in the snow and cloud ice water paths have opposing effects (Fig. 14a). In the tropics, on the other hand, there is some increase in the combined snow and cloud ice water path, since there is a slight increase in snow water path along with an increase in ice water path with increasing $D_{\mathrm{cs}}$ (see Fig. 14c and d). If TC4 is representative of the zonally averaged snow water path in the tropics, based on the analysis presented in Sect. 3, we suspect that the higher snow water path with larger $D_{\mathrm{cs}}$ is due to increases in snow at relatively high temperatures, i.e. lower altitudes (not shown). However, it is clear from all the parameters shown in Fig. 14 that the change in cloud ice water path is one of the main controlling factor in the changes to LWCF (Fig. 13b). For example, details such as the clustering of cloud ice water path for the simulations with $D_{\mathrm{cs}}$ less than $250 \mu \mathrm{m}$ are closely mirrored in LWCF.

SWCF is also a function of liquid, snow and cloud ice water paths and effective radii. Figure 13a shows that the response of SWCF to changes in $D_{\mathrm{cs}}$ has opposite effects in mid-latitudes compared to the tropics. By comparing Fig. 13a with Fig. 14, it is clear that the cloud liquid water path is the primary controlling factor in explaining the SWCF changes. Snow water path has some of the same variations as cloud liquid water path with $D_{\mathrm{cs}}$ (higher water path in tropics with increasing $D_{\mathrm{cs}}$ and lower in the mid-latitudes). However, overall changes in the cloud liquid water path with $D_{\text {cs }}$ mirror changes in SWCF closer than changes in snow 

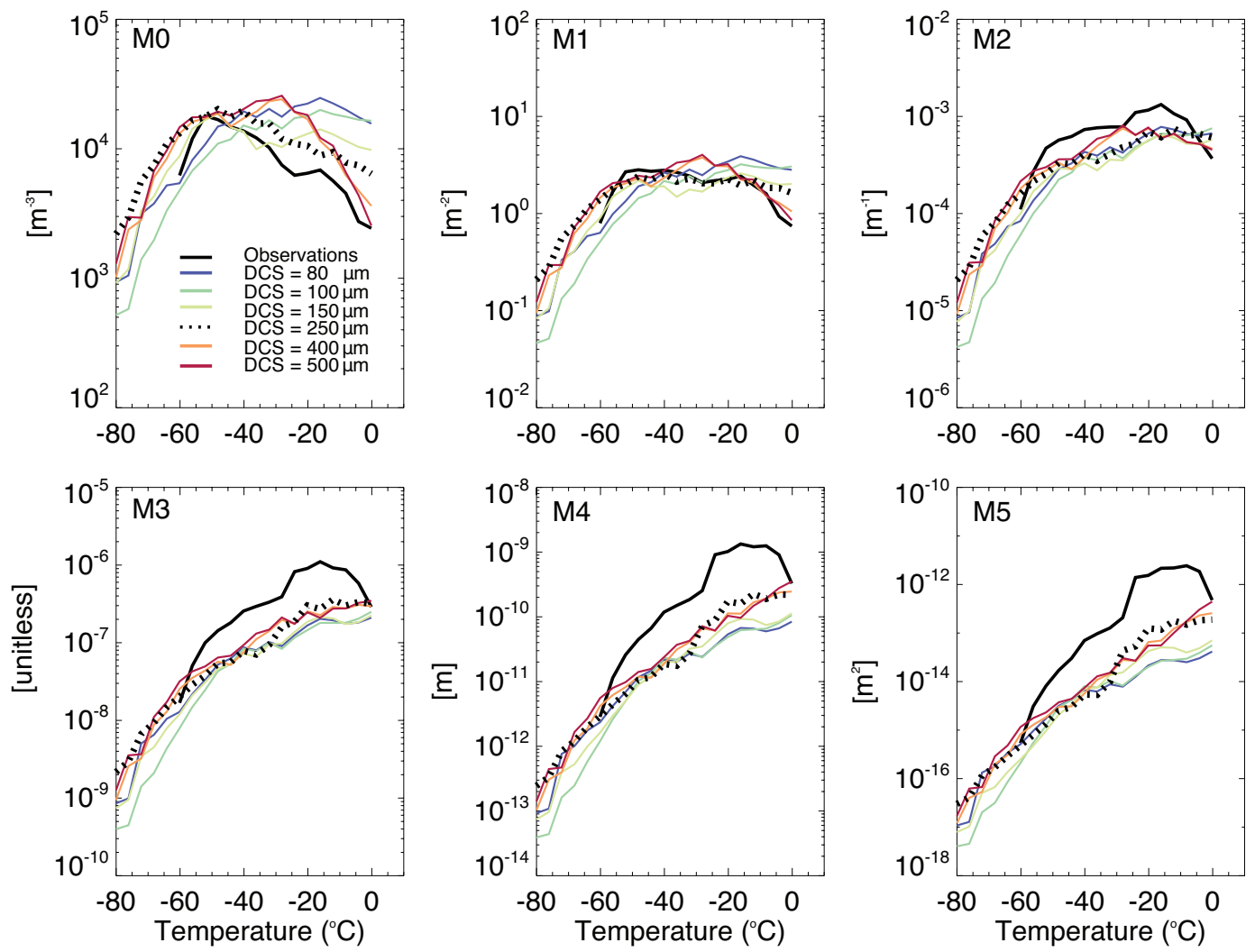

Figure 11. Same as Fig. 5 (moments, TC4), but using different $D_{\text {cs }}$ values.
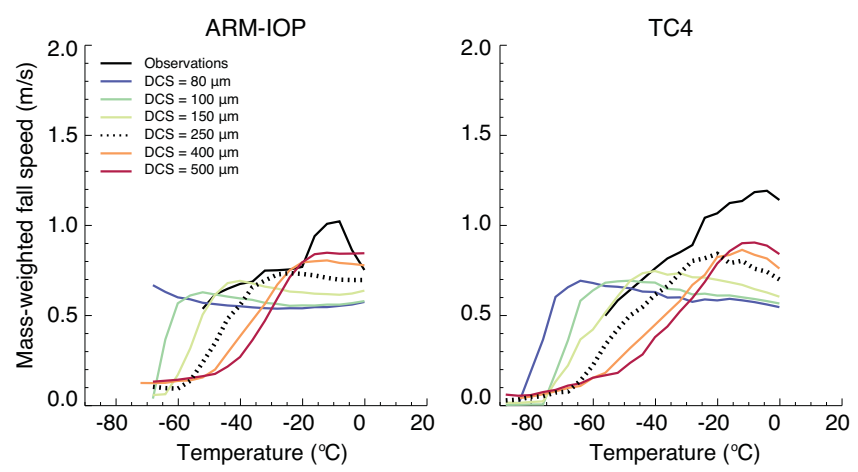

Figure 12. Same as Figs. 7 and 8 , but using different $D_{\mathrm{cs}}$ values.

water path. Thus, the shortwave cloud-forcing response appears to be mostly explained by indirect impacts of $D_{\mathrm{cs}}$ on liquid water path rather than directly through changes in the cloud ice and snow radiative properties. Furthermore, there is little correspondence between changes in the effective radii of snow, cloud ice, or liquid and SWCF with modification of $D_{\text {cs. }}$ This is seen in Figs. 13-14, which show little correspondence between changes in effective radii and SWCF, compared to changes in liquid water path.

Finally, we show the zonally averaged total cloud radiative forcing (TCF, SWCF+LWCF) in Fig. 15. Overall, the magnitude of TCF decreases with increasing $D_{\mathrm{cs}}$, moving the modeled TCF closer to CERES observations. However, the magnitude of the modeled TCF is still over-estimated compared to the observations in the tropics and into the midlatitudes. Only in a small window in the southern hemisphere $\left(-60\right.$ to $-70^{\circ}$ ) do $D_{\text {cs }}$ cases $\leq 250 \mu \mathrm{m}$ compare well with the observations. In summary, variations in $D_{\mathrm{cs}}$ impose a relatively large change in cloud radiative forcing, but none of the values tested here notably improve the modeled cloud radiative forcing compared to observations.

\section{Summary and conclusions}

We have presented a GCM - observational comparison of important ice microphysical parameters, such as the size distribution slope parameter, moments of the snow and ice particle size distributions, and mass-weighted fall speed. These parameters are closely linked to the direct radiative forcing of cloud ice and snow, and also have important indirect effects by impacting cloud liquid. It is therefore crucial to obtain a good agreement between model and observations of snow and ice size distributions parameters in the model, in order to conduct climate impact studies.

We used CAM5 with MG1.5 microphysics for this study. The aircraft observations were collected during TC4 (tropical 

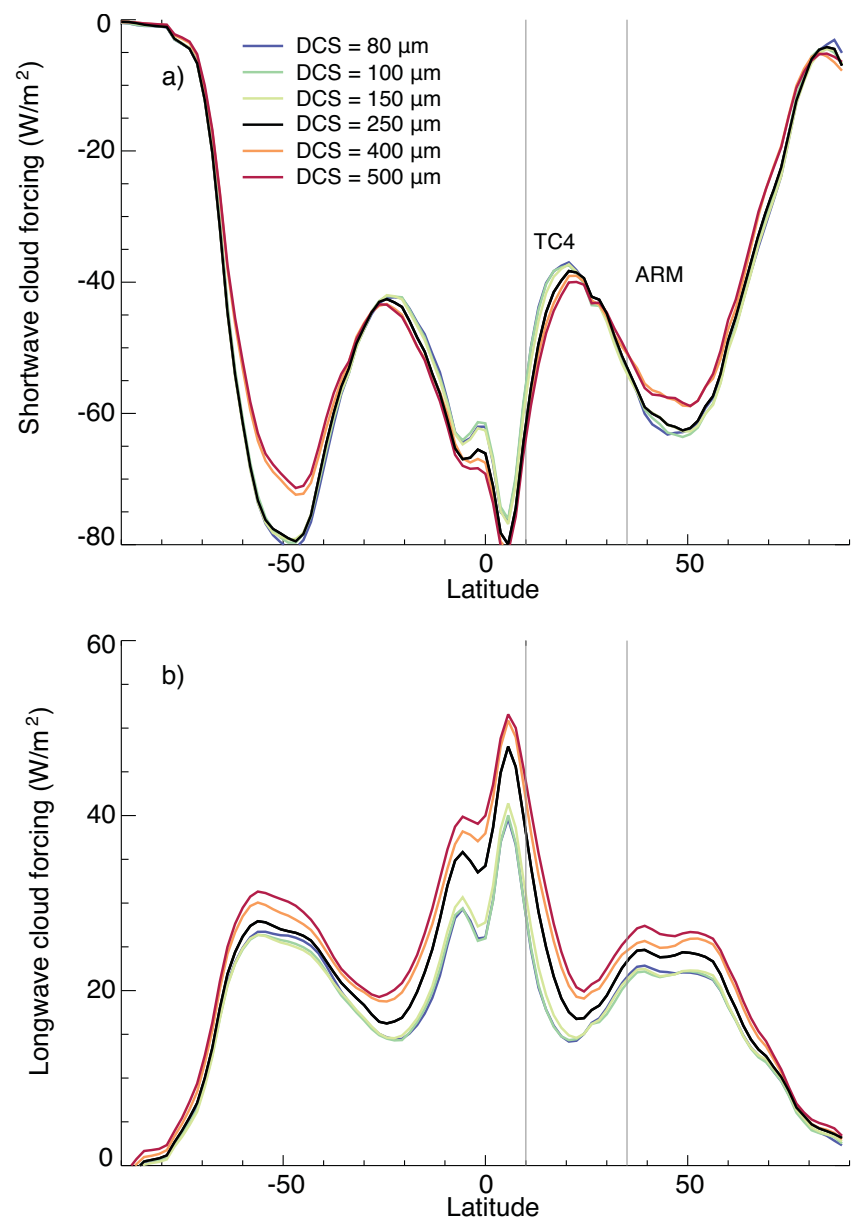

Figure 13. Zonal averaged shortwave and longwave radiative cloud forcing for the six runs, varying $D_{\mathrm{cs}}$.

anvil cirrus) and ARM-IOP (mid-latitude continental in-situ generated cirrus)

Our results with the control simulation $\left(D_{\mathrm{cs}}=250 \mu \mathrm{m}\right)$ indicate that the slope parameter in MG1.5 is about a factor of 2 higher than that determined from observations. This is true for both regions. However, the trend with temperature is comparable. For the moments, the model generates about a factor of 2 larger ice crystal number concentrations (ice plus snow, and for particles larger than $75 \mu \mathrm{m}$ ) at relatively high temperatures, while the ARM-IOP case indicates that the model generates too few crystals at low temperatures. We hypothesize this results from too many ice crystals formed heterogeneously at temperatures $<-37^{\circ} \mathrm{C}$, so that the competition between homogeneous and heterogeneous nucleation does not allow for homogeneously formed ice crystals. This is consistent with Zhang et al. (2013), who used SPARTICUS data in their evaluation of ice nucleation schemes in CAM5. The first moment has the best comparison between model and observations, while higher moments are generally under-predicted. The mass-weighted fall speeds were about a factor of 1.2 lower in the model compared to observations.
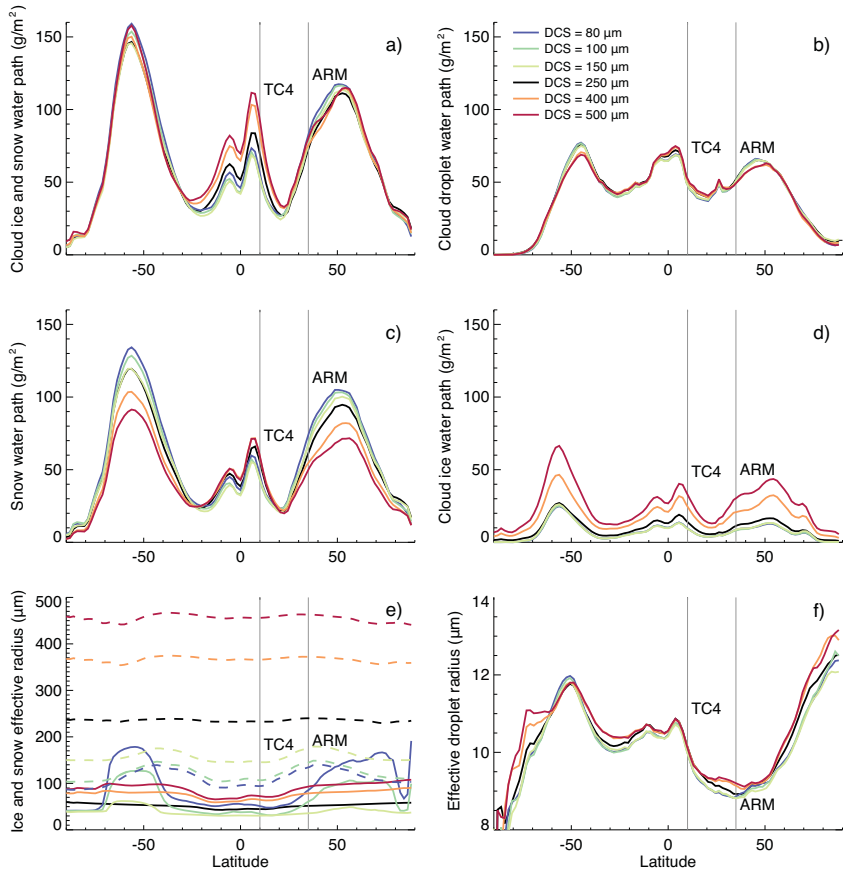

Figure 14. Zonal averaged cloud ice and snow water path (a), cloud droplet water path (b), snow water path (c), cloud ice water path (d), ice (solid) and snow (dashed) effective radius (e) and effective droplet radius (d) for the six different $D_{\mathrm{cs}}$ simulations.

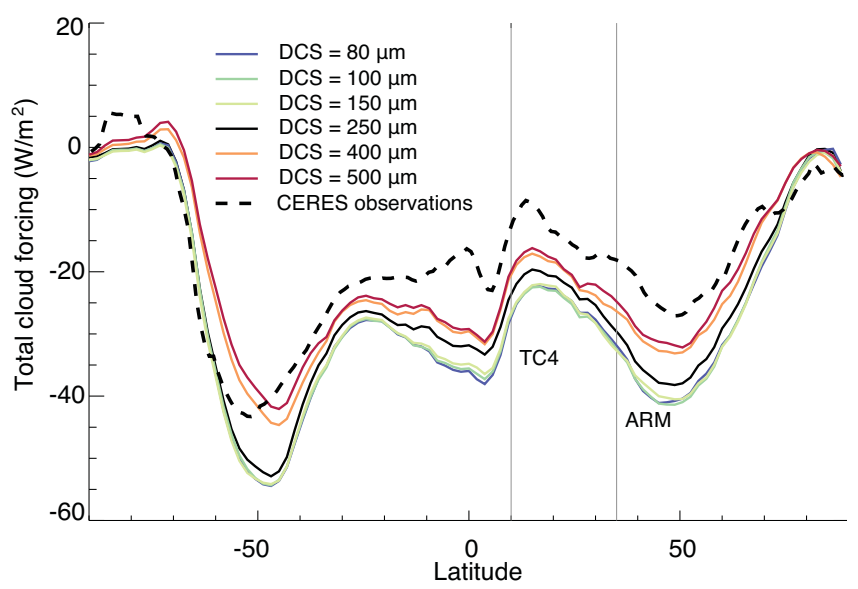

Figure 15. Total radiative cloud forcing $(\mathrm{LWCF}+\mathrm{SWCF})$. Dashed line is observed cloud radiative forcing from CERES.

In MG1.5, as in nearly all bulk microphysics schemes, ice is separated into cloud ice and snow categories with different particle densities and fall speed parameters. The size threshold for conversion of cloud ice to snow, $D_{\mathrm{cs}}$, is one of the main tuning parameters for cloud radiative forcing in CAM5. We conducted five additional simulations covering a large range of $D_{\mathrm{cs}}$ values. However, none of these simulations notably improved the comparison between the model and observations of the size distribution parameters 
and mass-weighted fall speed. We note that the snow is determined diagnostically in MG1.5 and therefore is assumed to be in steady state within a time step (i.e. the source and sink terms are equal to what is removed due to fallout). In this case, snow still undergoes processes such as sublimation, melting and riming. However, if snow was determined prognostically, the steady state assumption no longer applies and there is memory of snow mass and number mixing ratios across time steps. Thus, there could be differences in the sensitivity to $D_{\mathrm{cs}}$ in a prognostic snow scheme compared to the diagnostic snow scheme examined here. We note that prognostic rain and snow has now been included in CAM5 (Gettelman and Morrison, 2014; Gettelman et al., 2014).

The changes to $D_{\mathrm{cs}}$ also have large impacts on cloud radiative forcing. Changes in the total ice water path (cloud ice plus snow) with $D_{\text {cs }}$ were fairly small, especially in midlatitudes, because of opposing effects on the cloud ice and snow water paths. However, the longwave cloud radiative forcing is primarily influenced by cloud ice water path and hence the increase in cloud ice water path with increasing $D_{\mathrm{cs}}$ led to an increase in longwave cloud forcing. On the other hand, changes in the shortwave cloud forcing were mostly influenced by changes in cloud liquid water path indirectly driven by changes in $D_{\mathrm{cs}}$. Overall, there was a noticeable change in total cloud forcing when increasing $D_{\mathrm{cs}}$ from $250 \mu \mathrm{m}$, especially in the mid-latitudes. For example, there was a $10 \mathrm{Wm}^{-2}$ increase in total cloud radiative forcing in the southern mid-latitudes when $D_{\mathrm{cs}}$ was increased from $250 \mu \mathrm{m}$ to $400 \mu \mathrm{m}$. The changes were somewhat smaller in the mid-latitudes when decreasing $D_{\mathrm{cs}}$. None of the values of $D_{\mathrm{cs}}$ tested here led to notable improvement in the distribution of cloud radiative forcing.

Large sensitivity of the size distribution parameters and moments and mass-weighted fall speed, as well as cloud radiative forcing, to $D_{\mathrm{cs}}$ motivates additional work to improve how ice particle properties change with increasing particle size. This is especially true given that no particular value of $D_{\text {cs }}$ led to substantially better overall results. Furthermore, the autoconversion of cloud ice to snow, using the threshold size $D_{\mathrm{cs}}$, has little physical basis. One possible approach is to combine cloud ice and snow into a single category such as proposed by Morrison and Grabowski (2008), entirely removing the need for autoconversion. Ice particle mass-size and projected area-size relationships (from which fall speedsize relationship would be derived) would then vary across the particle size distribution to represent the different properties of small and large ice particles specified from observations. This would lead to some complications because simple analytic integrations, for example for the mass-weighted fall speed, are no longer possible. However, numerical integration can be performed with values stored in a lookup table (as used by Morrison and Grabowski, 2008), or with simplified expressions based on curve-fitting. Future work will explore these ideas.
Acknowledgements. The National Center for Atmospheric Research is sponsored by the US National Science Foundation (NSF). This work was supported by the US DOE ASR DE-SC0005336, subawarded through NASA NNX12AH90G.

Edited by: X. Liu

\section{References}

Barahona, D. and Nenes, A.: Parameterizing the competition between homogeneous and heterogeneous freezing in cirrus cloud formation - monodisperse ice nuclei, Atmos. Chem. Phys., 9, 369-381, doi:10.5194/acp-9-369-2009, 2009.

Del Genio, A. D., Yao, M.-S., Kovari, W., and Lo, K. K.-W.: A prognostic cloud water parameterization for climate models, J. Climate, 9, 270-304, 1996.

DeMott, P. J., Rogers, D. C., and Kreidenweis, S. M.: The susceptibility of ice formation in upper tropospheric clouds to insoluble aerosol components, J. Geophys. Res., 102, 19575-19584, 1997.

DeMott, P. J., Prenni, A. J., Liu, X., Kreidenweis, S. M., Petters, M. D., Twohy, C. H., Richardson, M. S., Eidhammer, T., and Rogers, D. C.: Predicting global atmospheric ice nuclei distributions and their impacts on climate, PNAS, 107, 11217-11222, 2010.

Dong, X., Mace, G. G., Minnis, P., Smith, W. L., Poellot, M., Marchand, R. T., and Rapp, A. D.: Comparison of stratus cloud properties deduced from surface, GOES, and aircraft data during the March 2000 ARM Cloud IOP, J. Atmos. Sci., 59, 3265-3284, 2002.

Eidhammer, T., DeMott, P. J., and Kreidenweis S. M.: A comparison of heterogeneous ice nucleation parameterizations using a parcel model framework, J. Geophys. Res., 114, D06202, doi:10.1029/2008JD011095, 2009.

Field, P. R., Heymsfield, A. J., and Bansemer, A.: Shattering and particle interarrival times measured by optical array probes in ice clouds, J. Atmos. Oceanic Technol., 23, 1357-1371, 2006

Fowler, L. D., Randall, D. A., and Rutledge, S. A.: Liquid and ice cloud microphysics in the CSU General Circulation Model. Part I: Model description and simulated microphysical processes, J. Climate, 9, 489-529, 1996.

Gettelman, A., Liu, X., Ghan, S. J., Morrison, H., Park, S., Conley, A. J., Klein, S. A., Boyle, J., Mitchell, D. L., and Li, J.-L. F.: Global simulations of ice nucleation and ice supersaturation with an improved cloud scheme in the Community Atmosphere Model, J. Geophys. Res., 115, D18216, doi:10.1029/2009JD013797, 2010 .

Gettelman, A. and Morrison, H: Advanced two-moment bulk microphysics for global models - Part 1: Off-line tests and comparison with other schemes, J. Climate, accepted, 2014

Gettelman, A., Morrison, H., Santos, S., Bogenschutz, P., and Caldwell, P. M.: Advanced two-moment bulk microphysics for global models - Part 2: Global model solutions and aerosol-cloud interactions, J. Climate, accepted, 2014.

Ghan, S. J. and Easter, R. C.: Computationally efficient approximations to stratiform cloud microphysics parameterization, Mon. Wea. Rev., 120, 1572-1582, 1992.

Ghan, S. J., Leung, L. R., and Easter, R. C.: Prediction of cloud droplet number in a general circulation model, J. Geophys. Res., 102, 21777-21794, 1997. 
Gierens, K.: On the transition between heterogeneous and homogeneous freezing, Atmos. Chem. Phys., 3, 437-446, doi:10.5194/acp-3-437-2003, 2003.

Heymsfield, A. J. and Westbrook, C. D.: Advances in the estimation of ice particle fall speeds using laboratory and field measurements, J. Atmos. Sci., 67, 2469-2482, 2010.

Heymsfield, A. J., Bansemer, A., and Twohy, C. H.: Refinements to ice particle mass dimensional and terminal velocity relationships for ice clouds, - Part I: Temperature dependence, J. Atmos. Sci., 64, 1047-1067, 2007.

Heymsfield, A. J., Schmitt, C., Bansemer, A., and Twohy, C. H.: Improved representation of ice particle masses based on observations in natural clouds, J. Atmos. Sci., 67, 3303-3318, 2010.

Heymsfield, A. J., Schmitt, C., and Bansemer, A.: Ice cloud particle size distributions and pressure-dependent terminal velocities from in situ observations at temperatures from 0 to $-86^{\circ} \mathrm{C}, \mathrm{J}$. Atmos. Sci., 70, 4123-4154, 2013.

Heymsfield, A. J., Winker, D., Avery, M., Vaughan, M., Diskin, G., Deng, M., Mitev, V., and Matthey, R.: Relationships between ice water content and volume extinction coefficient from in situ observations for temperatures from 0 to $-86^{\circ} \mathrm{C}$ : Implications for spaceborne lidar retrievals, J. Appl. Meteor. Clim., 53, 479-505, 2014.

Ikawa, M. and Saito, K.: Description of a non-hydrostatic model developed at the Forecast Research Department of the MRI, MRI Tech. Rep., 28, 238 pp., 1991.

Liu, X. and Penner, J. E.: Ice nucleation parameterization for global models, Meteorologische Zeitschrift, 14, 499-514, 2005.

Locatelli, J. D. and Hobbs, P. V.: Fall speeds and masses of solid precipitation particles, J. Geophys. Res., 79, 2185-2197, 1974.

Lohmann, U. and Roeckner, E.: Design and performance of a new cloud microphysics scheme developed for the ECHAM general circulation model, Climate Dyn., 12, 557-572, 1996.

Lohmann, U., Feichter, J., Chuang, C. C., and Penner, J. E.: Prediction of the number of cloud droplets in the ECHAM GCM, J. Geophys. Res., 104, 9169-9198, 1999.

Meyers, M.P., Demott, P. J., and Cotton, W. R.: New primary ice nucleation parameterizations in an explicit cloud model, J. Appl. Meteor., 31, 708-721, 1992.

Ming, Y., V. Ramaswamy, V., Donner, L. J., Phillips, V. T., Klein, S. A., Ginoux, P. A., and Horowitz, L. W.: Modeling the interactions between aerosols and liquid water clouds with a self-consistent cloud scheme in a general circulation model, J. Atmos. Sci., 64, 1189-1209, 2007.

Mitchell, D. L., Rasch, P., Ivanova, D., McFarquhar, G., and Nousiaisen, T.: Impact of small ice crystal assumptions on ice sedimentation rates in cirrus clouds and GCM simualtions, Geophys. Res. Lett., 35, L09806, doi:10.1029/2008GL033552, 2008.

Mitchell, D. L., Mishra, S., and Lawson. R. P.: Representing the ice fall speed in climate models: Results from Tropical Composition, Cloud and Climate Coupling (TC4) and the Indirect and Semi-Direct Aerosol Campaign (ISDAC), J. Geophys. Res., 116, D00T03, doi:10.1029/2010JD015433, 2011.

Morrison, H. and Gettelman, A.: A new two-moment bulk stratiform cloud microphysics scheme in the Community Atmosphere Model, Version 3 (CAM3) - Part I: Description and numerical tests, J. Clim., 21, 3642-3659, 2008.
Morrison, H. and Grabowski, W. W.: A novel approach for representing ice microphysics in models: description and tests using a kinematic framework, J. Atmos. Sci., 65, 1528-1548, 2008.

Neale, R. B., Chen, C.-C., Gettelman, A., Lauritzen, P. H., Park, S., Williamson, D. L., Conley, A. J., Garcia, R., Kinnison, D., Lamarque, J.-F., Marsh, D., Mills, M., Smith, A. K., Tilmes, S., Vitt, F., Cameron-Smith, P., Collins, W. D., Iacono, M. J., Easter, R. C., Ghan, S. J., Liu, X., Rasch, P. J., and Taylor, M. A.: Description of the NCAR Community Atmosphere Model (CAM 5.0), NCAR Tech. Note NCAR/TN-XXX+STR, Natl. Cent. for Atmos. Res, Boulder, Co, 282 pp., 2010.

Posselt, R. and Lohmann, U.: Introduction of prognostic rain in ECHAM5: design and single column model simulations, Atmos. Chem. Phys., 8, 2949-2963, doi:10.5194/acp-8-2949-2008, 2008.

Prenni, A. J., Harrington, J. Y., Tjernström, M., DeMott, P. J., Avramov, A., Long, C. N., Kreidenweis, S. M., Olsson, P. Q., and Verlinde, J.: Can ice nucleating aerosols affect Arctic seasonal climate?, Bull. Amer. Meteor. Soc., 88, 541-550, 2007.

Pruppacher, H. and Klett, J.: Microphysics of Clouds and Precipitation, 2nd edn., Kluwer Academic Publishers, Boston, MA, 1997.

Rasch, P. J. and Kristjansson, J. E.: A comparison of the CCM3 model climate using diagnosed and predicted condensate parameterizations, J. Climate, 11, 1587-1614, 1998.

Rotstayn, L. D.: A physically based scheme for the treatment of stratiform clouds and precipitation in large-scale models, I: Description and evaluation of the microphysical processes, Quart. J. Roy. Meteor. Soc., 123, 1227-1282, 1997.

Rotstayn, L. D., Ryan, B. F., and Katzfey, J. J.: A scheme for calculation of the liquid fraction in mixed-phase stratiform clouds in large-scale models, Mon. Wea. Rev., 128, 1070-1088, 2000.

Stephens, G. L.: Cloud feedbacks in the climate system: A critical review, J. Climate, 18, 1149-1152, 2005.

Strapp, J. W., Albers, F., Reuter, A., Korolev, A. V., Maixner, U., Rashke, E., and Vukovic, Z.: Laboratory measurements of the response of a PMS OAP-2DC, J. Atmos. Oceanic Technol., 18, 1150-1170, 2001.

Toon, O. B., Starr, D. O., Jensen, E. J., Newman, P. A., Platnick, S., Schoeberl, M. R., Wennberg, P. O., Wofsy, S. C., Kurylo, M. J., Maring, H., Jucks, K. W., Craig, M. S., Vasques, M. F., Pfis- ter, L., Rosenlof, K. H., Selkirk, H. B., Colarco, P. R., Kawa, S. R., Mace, G. G., Minnis, P., and Pickering, K. E.: Planning, implementation, and first results of the Tropical Composition, Cloud and Climate Coupling Experiment (TC4), J. Geophys. Res., 115, D00J04, doi:10.1029/2009JD013073, 2010.

Zhang, K., Liu, X., Wang, M., Comstock, J. M., Mitchell, D. L., Mishra, S., and Mace, G. G.: Evaluating and constraining ice cloud parameterizations in CAM5 using aircraft measurements from the SPARTICUS campaign, Atmos. Chem. Phys., 13, 4963-4982, doi:10.5194/acp-13-4963-2013, 2013.

Zhao, C., Liu, X., Qian, Y., Yoon, J., Hou, Z., Lin, G., McFarlane, S., Wang, H., Yang, B., Ma, P.-L., Yan, H., and Bao, J.: A sensitivity study of radiative fluxes at the top of atmosphere to cloud-microphysics and aerosol parameters in the community atmosphere model CAM5, Atmos. Chem. Phys., 13, 10969-10987, doi:10.5194/acp-13-10969-2013, 2013. 